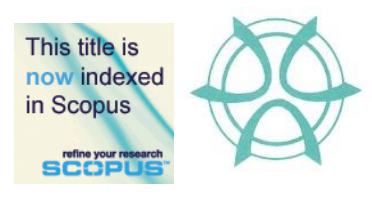

PLANNING MALAYSIA:

Journal of the Malaysian Institute of Planners

VOLUME XIV (2016), Page 67 - 80

\title{
WHAT BRINGS YOUTH TO RECREATIONAL PARKS?
}

\author{
Rosilawati Zainol $^{1} \&$ Cheong Peng Au-Yong ${ }^{2}$ \\ ${ }^{I}$ Department of Urban and Regional Planning, Faculty of Built Environment \\ ${ }^{2}$ Department of Building Surveying, Faculty of Built Environment \\ UNIVERSITY OF MALAYA
}

\begin{abstract}
Locations of recreational parks are said to have a direct influence on youth physical activities. However, there is still a lack of studies on youth activities at recreational parks. Thus, this study examines the relationship between reasons and habit of youth going to recreational parks through a questionnaire survey. Variables that are measured include enjoying the outdoors, use a particular facility at the park, play sports, picnic and general activities, walk or ride a bicycle for exercise and meeting friends. Logistic regression analysis reveals youths are most likely to visit the park for playing sports, walking or riding a bicycle, provided the facilities and amenities are available. Hence, planning, implementation and maintenance of recreational park play a significant role in promoting outdoor activities and active lifestyle among the youth.
\end{abstract}

Keyword: physical activity, recreational facilities, habit, youth, recreational parks, logistic regression analysis 
Rosilawati Zainol \& Cheong Peng Au-Yong

What Brings Youth to Recreational Parks?

\section{INTRODUCTION}

The rapid advancement of information technology in the millennium period has changed the way people live today, and this has impacts on everyone including youth (United Nations, 2005). Youth is a young person aged between 15 and 24 years old (United Nations Education, 2009-2014) and is sensitive towards the introduction of new technology. The current youth generation was born with technology surrounding them (Mesch, 2009). It is rather alarming to note that a study carried out in the United States discovers American youth aged 8 to 18 years old, spent 8.08 hours a day consuming on various types of media. The types of media include television, video game, recorded music, computer, cell phones and the internet and the total media usage has been on the increase since 1999 (Rideout, Foehr, \& Roberts, 2010). Watching television, video game, listening to a music recorder, playing computer and other inactive activities are examples of sedentary activities (Bennett, Winters-Stone, Nail, \& Scherer, 2006; Pate, O'Neill, \& Lobelo, 2008). Watching television daily for more than two hours is unhealthy as it can lead to not only reduced physical and psychosocial health but also may result in increased risk of cardio-metabolic disease and high body mass index (BMI) (Proper, Singh, Mechelen, \& Chinapaw, 2011; Tremblay et al., 2011).

Also, the insufficient physical activity can also result in high rates of obesity (Babey, Hastert, Yu, \& Brown, 2008). More than 1.9 billion people aged 18 years and above are estimated to be overweight and more than 600 million were obese (World Health Organization, 2015). The rate of obesity is more than double since 1980 until 2014 globally. Therefore, youth needs to reduce sedentary behaviour and acquire active living to prevent such diseases. Proper et al. (2011) also propose that interventions intended to reduce sedentary behaviour are required. Thus, playing sports at recreational parks, for example, can reduce body mass index (BMI) and promote healthy living (Zulkia, Zainol, Zainol, Nordin, \& Ahmad, 2014).

Despite the highlights on the benefits of physical activities, recent studies have shown that youth makes little use of recreational parks (Gardsjord, Tveit, \& Nordh, 2014; Loukaitou-Sideris \& Sideris, 2009). These are due to several factors which include lack of interest in the current park activities, lack of time, safety, accessibility, recreational facilities, maintenance and renovation (Cohen et al., 2009; Gardsjord et al., 2014; Loukaitou-Sideris \& Sideris, 2009). While studies have shown the lack of interests in park activities, some of these factors may have positive impacts on youth's motivation to go to the parks. Also, parks are also able to provide social cohesion. It offers local daily experiences shared by a variety of people. It also promotes intercultural interactions (Peters, Elands, \& Buijs, 2010).

Therefore, this study intends to examine the relationship between reasons and habit of youth going to recreational parks. 
PLANNING MALAYSIA

Journal of the Malaysian Institute of Planners (2016)

\section{YOUTH AND PHYSICAL ACTIVITY}

There are two categories of young people according to age. First, the category is teenagers whose age is between 15-19 years. The balance aged 20-24 years old is considered young adolescents. Between these two groups, the former is most hit by the impact of technologies (Tremblay et al., 2011). They have the most leisure time as compared to another youth group. Youth always tries to find new ways to fulfil their leisure time both out of necessity and of choice. According to United Nations (2005), leisure time plays a vital role in promoting social inclusion, access to opportunities and overall development among young people. Thus, this leisure time should be fulfilled with beneficially as it may have a high impact on youth development mentally and physically (United Nation, 2004).

According to Garsjord et al. (2014), people are more active physically if they were physically active during their teenage years. Therefore fulfilling leisure time productively with promoting active living among youth will results in higher number of active life among adults at a later time. Physical activity behaviour refers to active recreation such as playing football and participating in other active activities (Must \& Tybor, 2005) and active living equals to a healthy lifestyle (Edwards \& Tsouros, 2006). Previous studies have shown youths are attracted to low cost and well-maintained facilities and also active young participants (Ries, Gittelsohn, Voorhees, Roche, Clifton, \& Astone (2008). A study by Wilson, Williams, Evans, Mixon and Rheaume (2005) shows, boys prefer playing basketball, football, soccer and baseball. Girls, on the other hand, prefer playing basketball, swimming and roller-skating. This may differ based on cultural background.

Sedentary behaviour, however, refers to a passive recreation activity such as watching television and playing online games (Must \& Tybor, 2005). However, the current pattern shows low participation among them for active recreational activities (Heath, Pratt \& Kann, 1994). Also, previous studies have also found girls are less fit than boys due to the amount of time spent on passive recreation by the former contributes to this matter further (James \& Embrey, 2002; Raithel, 1987). This behaviour can be reduced among youth if parks are located with the proximity of the neighbourhood and they participate in physical activities (Epstein et al., 2006).

\section{Influencing Factors That Affect Youth Decision to Go to Recreational Parks}

The availability of parks nearby their homes influences the youth's physical activities directly. Studies by Cohen et al. (2009), Cohen et al. (2006), Kirby, Levin, and Inchley (2013) and Ries et al. (2009) found that park availability and proximity are crucial to youth's physical activity. Gardsjord et al. (2014) discover that studies on access to green space by youth have received a lot of attention by 
Rosilawati Zainol \& Cheong Peng Au-Yong

What Brings Youth to Recreational Parks?

many scholars. The higher green space coverage and the closer the distance, the greater number of youth will be using the park. Nevertheless, safety (Heitzler, Martin, Duke, \& Huhman, 2006; Holt et al., 2009; Loukaitou-Sideris \& Sideris, 2009) and maintenance of facilities (Humbert et al., 2006; Loukaitou-Sideris \& Sideris, 2009) also have an impact on the frequency of youth's visiting the park.

Besides sites, facilities and safety, ability to perform physical activities also play a significant role in attracting youth to recreational parks (Baran et al., 2013). The use of the park by youth is strongly associated with organised after school activities and identification of a team motivator (Perry, Saelens, \& Thompson, 2011).

\section{METHODOLOGY}

This study employs a quantitative approach. A questionnaire survey was carried out at all recreational parks that provide youth's facilities such as football/rugby field, badminton court, street soccer court, basketball court and skateboard plane in Subang Jaya, Selangor. This survey was conducted from October 2014 to December 2014.

\section{Study Area}

Subang Jaya is a township managed by the Subang Jaya Municipal Council. It consists of Old Subang Jaya and USJ. Subang Jaya township was the fastest growing community in the Petaling District between 1991 and 2000. It has a total population of 170,498 , the highest number of population as compared to other towns under the same local authority (Department of Statistics, 2010). Subang Jaya has 33,144 youths, the largest number of youth aged 15 to 24 years old as compared to other nearby townships.

There are about 174 recreational parks in Subang Jaya USJ. These include playground, playing field, neighbourhood park, local park and urban park. However, not all of the parks provide facilities for the youth. Facilities that youth required include a basketball court, street soccer court, badminton court, football field, skateboard platform other than jogging track and bicycle path. Some of the parks may even provide outdoor gymnasium set. Figure 1 shows the location of all recreational parks that provide facilities for youth.

\section{Sampling}

This study involved respondents aged 15 to 24 years old. The distribution of questionnaire survey adopted simple random sampling method within the research population of 33,144. This approach enhances the equal chance of the sample to be selected randomly (Saris \& Gallhofer, 2007). Overall, 397 respondents participated in this study. They were randomly chosen at all the recreational parks that attract youth. Krejcie \& Morgan (1970) stated that the 
PLANNING MALAYSIA

Journal of the Malaysian Institute of Planners (2016)

minimum sample size for a population of 40,000 should not less than 380 . Thus, the sample size for this study is acceptable and valid.

\section{Data Collection}

Data collection was based on questionnaire consisted of multiple-choice questions, Likert-scale questions and open-ended questions. The first section of the questionnaire inquiries about respondent information and the second section asks about the visits to recreational parks.

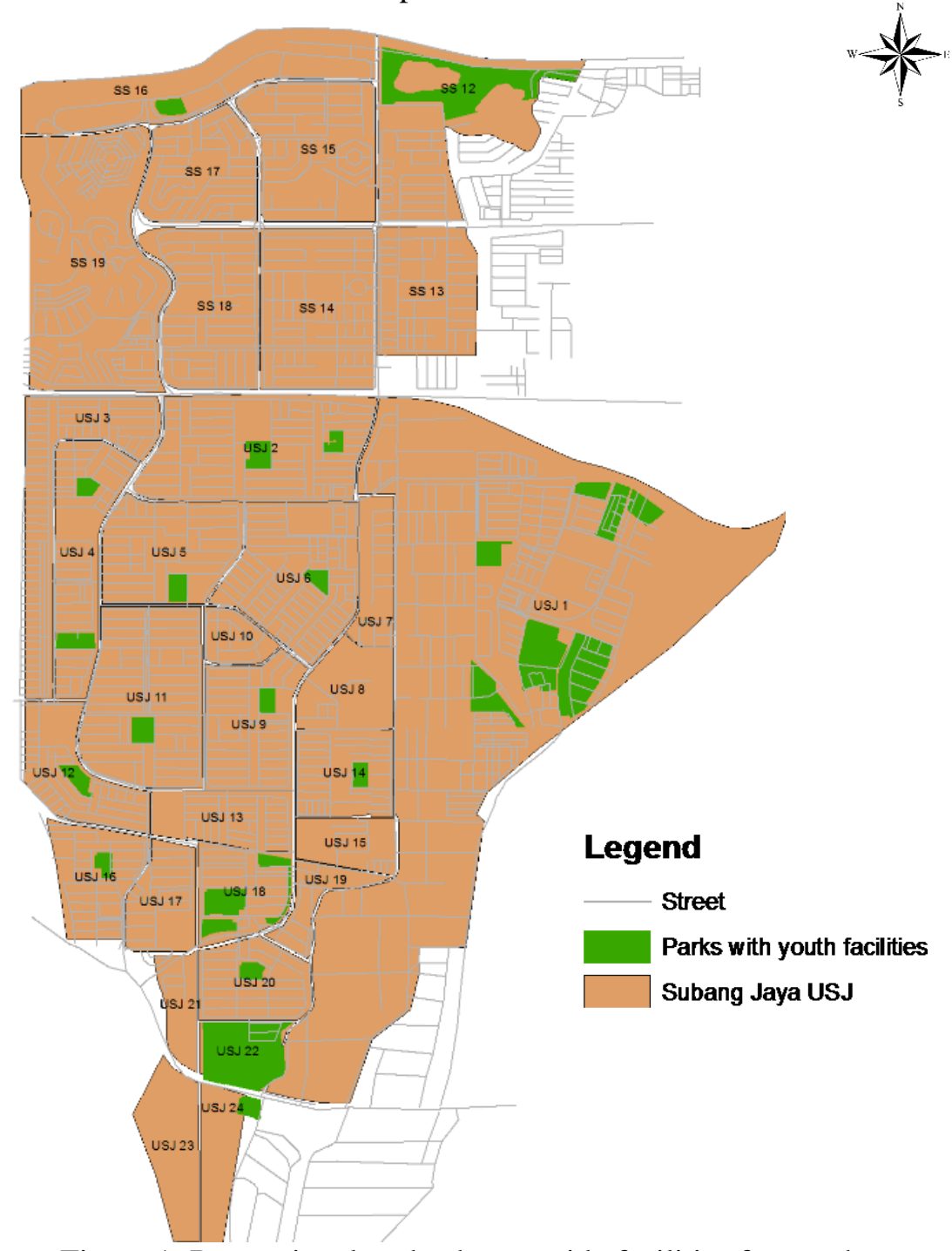

Figure 1: Recreational parks that provide facilities for youth Source: Field study, 2015 
Rosilawati Zainol \& Cheong Peng Au-Yong

What Brings Youth to Recreational Parks?

\section{Method of Analysis}

The reliability analysis is conducted for the variables of reason to visit the park to confirm the reliability of data. The purpose of this test is to examine the constancy of the scale of data (Leech, Barrett, \& Morgan, 2011). The Cronbach's alpha coefficient for the reasons of going to park is 0.784 . The coefficient of more than 0.70 indicates good reliability.

Spearman rank-order correlation test is run to establish the relationship between the reasons and habit of going to the park via Statistical Package for Social Science (SPSS) (Diamond \& Jefferies, 2006). It is appropriate to analyse either or both ordinal variables (Graziano \& Raulin, 2010).

Subsequently, this research adopts the binary logistic regression to formulate the prediction model for the habit of going to the park. Whereby, the logistic regression measures the probability of an event (Chua, 2009). Theoretically, the equation of logistic regression is as follow:

$$
Z=\beta_{0}+\beta_{1} X_{1}+\beta_{2} X_{2}+\ldots \ldots+\beta_{\mathrm{k}} X_{\mathrm{k}}+\varepsilon
$$

Where,

$Z=$ latent variable

$X_{1}, X_{2}, \ldots \ldots, X_{\mathrm{k}}=$ independent variables

$\beta_{0}=$ constant

$\beta_{1}, \beta_{2}, \ldots \ldots, \beta_{\mathrm{k}}=$ change in $Y$ for a change of one unit in $X_{1}, X_{2}, \ldots \ldots, X_{\mathrm{k}}$ respectively

$\varepsilon=$ error term

$Z$ value is computed using a link function to find out the probability of the event occurring. In this study, the link function to obtain the probability of the habit is as follows:

$\mathrm{P}$ [habit of going to park] $=e^{z} / 1+e^{z}$, the value is between 0 and 1 .

\section{RESULTS AND DISCUSSION}

In this study, the respondents are the youth in different ages. The mean age of the respondents is 18.99; while the mode of the respondents' age is 19 , which covers 13.6 percent of the total respondents. Then, more than half of the respondents (59.9 percent) are at the age range of 15 to 19 . The majority of the youth at this age range are still studying in secondary or high school. They have more leisure time to visit the recreational park. On the other hand, the majority of the youth at the age of 20 to 24 are either studying in higher-level education institution (college/university) or working in the community. So, they tend to have lesser leisure time. 
PLANNING MALAYSIA

Journal of the Malaysian Institute of Planners (2016)

\section{Relationship between Reasons and Habit of Going to Park}

There are eight reasons of going to park identified as the independent variables; while the habit of going to park as the dependent variable. The relationship between the reasons and habit of going to park is then analysed through correlation analysis as shown in Table 1. Generally, below 0.3 correlation coefficient indicates weak relationship; 0.3 to 0.5 coefficient reflects moderate relationship; and above 0.5 coefficient shows a strong relationship between two variables (Gray \& Kinnear, 2012; Saunders, Lewis, \& Thornhill, 2009). Nevertheless, SPSS confirms the significant relationship between two variables with the significance value of 0.05 or below. The test identifies six independent variables that are significantly correlated to the habit of going to park, namely:

- Enjoy the outdoors or nature

- Use a particular facility at a park

- Play sports

- Picnic and general leisure activities

- Walk or ride a bicycle for exercise

- Meet friends

Table 1 Correlation analysis between reasons and habit of going to park

\begin{tabular}{lll}
\hline Reason & Habit of Going to Park & \\
\cline { 2 - 3 } & Correlation Coefficient & Sig. (2-tailed) \\
\hline Enjoy the outdoors or nature & $0.197^{* *}$ & 0.000 \\
Use a particular facility at a park & $0.261^{* *}$ & 0.000 \\
Play sports & $0.404^{* *}$ & 0.000 \\
Picnic and general leisure activities & $0.102^{*}$ & 0.042 \\
Walk or ride a bicycle for exercise & $0.210^{* *}$ & 0.000 \\
Meet friends & $0.166^{* *}$ & 0.001 \\
Participate in family activities & 0.068 & 0.178 \\
Attend special events concerts & 0.023 & 0.645 \\
\hline$* *$ Correlation is significant at the 0.01 level (2-tailed). \\
*. Correlation is significant at the 0.05 level (2-tailed). \\
\hline
\end{tabular}

Indeed, the significant relationships as shown in Table 1 can reflect the action to be taken for improving the recreational parks. The main reason of the youth going to the park is to play sports, at a correlation coefficient of 0.404 ( $\mathrm{p}<$ 0.01 ). The result demonstrates that the youth visit to the recreational park to use the available sports facilities, such as football field, basketball court, badminton court, and others. It reflects the need of having sports facilities at the recreational park to attract the visits of youth. Thus, the result supports the study outcomes by Cohen et al. (2009), Cohen et al. (2006), Kirby et al. (2013) and Ries et al. (2009), which revealed the necessity of park availability to youth's physical activities. 
Rosilawati Zainol \& Cheong Peng Au-Yong

What Brings Youth to Recreational Parks?

Then, another significant reason of youth visiting the park is to use a particular facility at the park $(r=0.261, p<0.01)$. For instance, they go to the park for skateboarding, using gymnasium facilities, and others. Thus, availability of these specific facilities can be an attraction point for the youth to visit the park. These activities are indeed the physical activities that can promote an active lifestyle. Some people might see these activities as an entertainment and help in releasing stress. Again, the findings validate the statements of Cohen et al. (2009), Cohen et al. (2006), Kirby et al. (2013) and Ries et al. (2009).

Thirdly, walking or riding a bicycle for exercise is a significant reason for youth to visit the park, with correlation coefficient 0.210 ( $\mathrm{p}<0.01)$. Walking and biking are the common activities done by the public, including the youth. Availability of walking and riding paths are the most important criterion to promote these activities. Also, to promote more physical activities like walking and biking, the recreational park should always be equipped with walking and biking paths. Meanwhile, they must always be in good and safe conditions as mentioned by Heitzler et al., (2006), Holt et al. (2009) Loukaitou-Sideris \& Sideris (2009) and Humbert et al. (2006).

Furthermore, the youth like to enjoy outdoor and nature views, provided there are some attractive features. For instance, the recreational park with beautiful landscaping, water features, or nature scenery would attract more people to visit. Many recreational parks become tourist spot because of their beautiful nature features. Inevitably, the findings confirm the statement of Gardsjord et al. (2014), showing that the youth tends to visit the park for enjoying outdoor and nature scenery, at a correlation coefficient of 0.197 ( $p<0.01$ ).

In fact, the visit of youth to the park for the discussed activities requires the availability of facilities or features at the recreational park. Hence, planning of recreational park plays a significant role in promoting the outdoor activities and active lifestyle among the youth.

\section{Prediction Model on Habit of Going to Park}

According to the correlation analysis result, six reasons of going to park are found to be significantly correlated with the habit of going to park. Logistic regression analysis is run using the six significant reasons as the predictors, to confirm the correlation analysis result and to demonstrate the significant predictors of the habit of going to park. Then, the test will include all the significant predictors (with a significant value of less than 0.05) in and exclude all the insignificant predictors (with a significant value of more than 0.05 ) from the prediction model.

In the analysis, the habit of going to park is coded with the value 0 and 1. Whereby, "no" and "yes" are labelled as 0 and 1 respectively. By using the forward stepwise method, SPSS produces two steps to include the predictors that significantly contribute to the logistic regression model. Step one reveals that play sports significantly predicts the odds of the habit of going to park with $X^{2}=80.76$, 
PLANNING MALAYSIA

Journal of the Malaysian Institute of Planners (2016)

$\mathrm{p}<0.05$. Then, Step 2 computes the walking or riding with $X^{2}=5.20, \mathrm{p}<0.05$. Thus, there are two independent variables significantly predicting the habit of going to park $\left(X^{2}=85.96, \mathrm{p}<0.05\right)$.

In this case, $40.6 \%$ of the habit can be predicted from the reason of playing sports (PS) and walking or riding (WR). Overall, the model predicts 91.4\% of the cases correctly (see Table 2). Meanwhile, the p-value for HosmerLemeshow goodness of fit is 0.773 , which is more than 0.05 . Therefore, the model adequately fits the data. Then, the logistic regression equation is produced as follows (see Table 3):

$$
\mathrm{Z}=-4.677+0.805 \mathrm{PS}+0.209 \mathrm{WR}
$$

As a result, play sports and walking or riding are the significant reasons that are influencing the probability of habit of going to park. To further increase the occupancy or usage rate of the parks, relevant authorities may enhance the amenities of parks based on the significant reasons of the youth to visit the parks. Previous studies have also highlighted the issues of attracting youth to recreational parks by providing more amenities (Floyd et al., 2011) and proper maintenance of facilities (Humbert et al., 2006; Loukaitou-Sideris \& Sideris, 2009). Organised activities at the park such as playing sports affect youth's likely reasons to go to the park (Perry et al., 2011).

Table 2 Classification table

\begin{tabular}{|c|c|c|c|c|c|}
\hline & & & \multicolumn{3}{|c|}{ Predicted } \\
\hline & & & \multicolumn{2}{|c|}{ Go Park } & \multirow{2}{*}{$\begin{array}{l}\text {-Percentage } \\
\text { Correct }\end{array}$} \\
\hline & \multicolumn{2}{|c|}{ Observed } & No & Yes & \\
\hline \multirow[t]{2}{*}{$\overline{\text { Step } 1}$} & Go Park & No & 12 & 28 & 30.0 \\
\hline & Overall $\mathrm{F}$ & $\begin{array}{l}\text { Yes } \\
\text { ntage }\end{array}$ & 7 & 350 & $\begin{array}{l}98.0 \\
91.2\end{array}$ \\
\hline \multirow[t]{2}{*}{ Step 2} & Go Park & No & 12 & 28 & 30.0 \\
\hline & Overall $\mathrm{F}$ & $\begin{array}{l}\text { Yes } \\
\text { ntage }\end{array}$ & 6 & 351 & $\begin{array}{l}98.3 \\
91.4\end{array}$ \\
\hline
\end{tabular}


Rosilawati Zainol \& Cheong Peng Au-Yong

What Brings Youth to Recreational Parks?

Table 3 Variables in the equation

\begin{tabular}{llllllll}
\hline & & B & S.E. & Wald & df & Sig. & Exp(B) \\
\hline Step 1 $^{\text {a }}$ & Play Sports & 0.845 & 0.113 & 55.833 & 1 & 0.000 & 2.328 \\
& Constant & -3.684 & 0.741 & 24.708 & 1 & 0.000 & 0.025 \\
Step 2 & Play Sports & 0.805 & 0.115 & 49.359 & 1 & 0.000 & 2.236 \\
& Walking/Riding & 0.209 & 0.090 & 5.351 & 1 & 0.021 & 1.232 \\
& Constant & -4.677 & 0.907 & 26.591 & 1 & 0.000 & 0.009 \\
\hline
\end{tabular}

a. Variable(s) entered on step 1: Play Sports.

b. Variable(s) entered on step 2: Walking/Riding.

\section{RECOMMENDATIONS}

To attract the youth to visit the parks, planning and provision of park amenities must be improved to fulfil the needs of them. This study demonstrates the main reasons for youth to visit the park include play sports and walking or riding. So, proper amenities can be proposed to the planning of recreational parks. For example, the planning authorities may recommend the sports facilities in the parks, such the football field, basketball court, futsal court, badminton court, and others. Moreover, the planning of walking and riding paths must be appropriate including the width, capacity, connectivity, accessibility, quality and condition, availability of shade or covered path, availability of street furniture, lighting and others.

Further study is recommended to explore the type of sports that are popular in different geographical areas, as well as the design of the walking and riding paths that the users are seeking. By fulfilling the requirements of the users, the occupancy and usage rate of the parks will be increasing significantly.

In addition, local authorities, society, city leaders and decision makers are responsible for ensuring active living among youth and the leisure needs of young people must be considered in the process of urban planning and rural development (United Nations, 2005). Currently, it is encouraged that youth participates in community development decision-making as their voices and engagement can help improve planning outcomes (Santo et al. 2010; Passon et al. 2008).

\section{CONCLUSION}

Promoting physical activities among youth will help reduce the number of obesity among them. Since youths who are active in their younger age will most likely stay active when they are older, the number of obesity among adults also can be reduced. In addition, visits to the parks and actively participating in physical activities will also promote social integration among them. Therefore, the availability of facilities and amenities in the recreational parks is of important to attract the visit by youth. Also, the facilities and amenities at these parks should 
be maintained and monitored regularly. Local authorities and community associations should also engage youth in their planning for youth activities.

\section{ACKNOWLEDGEMENTS}

Authors wish to thank all group members of the University of Malaya and the Ministry of Education for grant no. ER017/2012A.

\section{REFERENCES}

Babey, S. H., Hastert, T. A., Yu, H. \& Brown, E. R. (2008). Physical activity among adolencents: when do parks matter? American Journal of Preventive Medicine, 34(4), 345-348.

Baran, P. K., Smith, W. R., Moore, R. C., Floyd, M. F., Bocarro, J. N., Cosco, N. G. \& Danninger, T. M. (2013). Park use among youth and adults: examination of individual, social, and urban form factors. Environment and Behavior. doi: 10.1177/0013916512470134

Bennett, J. A., Winters-Stone, K, Nail, L. M., \& Scherer, J. (2006). Definitions of sedentary in physical-activity-intervention trials: a summary of the literature. $J$ Aging Phys Act., 14(4), 456-477.

Chua, Y. P. (2009). Statistik Penyelidikan Lanjutan: Ujian Regresi, Analisa Faktor dan Analisis Sem Buku 5. Kuala Lumpur: McGraw-Hill (Malaysia) Sdn. Bhd.

Cohen, D. A, Ashwood, J. S., Scott, M. M., Overton, A., Evenson, K. R., Staten, L. K., Porter, D. McKenzie, T. L. \& Catellier, D. (2006). Public parks and physical activity among dolescent girls. Pediatrics, 118(5), e1381-e1389.

Cohen, D., Golinelli, D., Williamson, S., Sehgal, A., Marsh, T. \& McKenzie, T. L. (2009). Effects of park improvements on park use and physical activity policy and programming implications. American Journal of Preventive Medicine, 37(6), 475-480.

Department of Statistics. (2010). Population Distribution by Local Authority Areas and Mukims. Putrajaya: Malaysian Department of Statistics.

Diamond, I. \& Jefferies, J. (2006). Beginning Statistics: An Introduction for Social Scientists. London: SAGE Publications Ltd.

Edwards, P. \& Tsouros, A. (2006). Promoting physical activity and active living in urban environments: the role of local governments The Solid Facts. Copenhagen, Denmark: World Health Organization Europe.

Epstein, L. H., Raja, S., Gold, S. S., Paluch, R. A., Pak, Y. \& Roemmich, J. N. (2006). Reducing sedentary behavior: the relationship between park area and the physical activity of youth. Psychological Science, 17(8), 654-659.

Floyd, M. F., Bocarro, J. N., Smith, W. R., Baran, P. K., Moore, R. C., Cosco, N. G., Edwards, M. B., Suau, L. J. \& Fang, K. (2011). Park-Based physical activity among children and adolescents. American Journal of Preventive Medicine, 41(3), 258-265. doi: http://dx.doi.org/10.1016/j.amepre.2011.04.013

Gardsjord, H. S., Tveit, M. S. \& Nordh, H. (2014). Promoting youth's physical activity through park design: linking theory and practice in a public health perspective. Landscape Research, 39(1), 70-81. doi: 10.1080/01426397.2013.793764 
Rosilawati Zainol \& Cheong Peng Au-Yong

What Brings Youth to Recreational Parks?

Gray, C. D. \& Kinnear, P. R. (2012). IBM SPSS statistics 19 made simple. East Sussex: Pyschology Press.

Graziano, A. M. \& Raulin, M. L. (2010). Research methods: a process of inquiry (7th ed.). Boston: Pearson Education Inc.

Heath, G. W., Pratt, M., Warren, C. W. \& Kann, L. (1994). Physical activity patterns in American high school students: Results from the 1990 youth risk behavior survey. Archives of Pediatrics \& Adolescent Medicine, 148(11), 1131-1136. doi: 10.1001/archpedi.1994.02170110017003

Heitzler, C. D., Martin, S. L., Duke, J. \& Huhman, M. (2006). Correlates of physical activity in a national sample of children aged 9-13 years. Preventive Medicine, 42(4), 254-260. doi: http://dx.doi.org/10.1016/j.ypmed.2006.01.010

Holt, N. L., Cunningham, C., Sehn, Z. L., Spence, J. C., Newton, A. S. \& Ball, G. C. (2009). Neighborhood physical activity opportunities for inner-city children and youth. Health \& Place, 15(4), 1022-1028. doi http://dx.doi.org/10.1016/j.healthplace.2009.04.002

Humbert, M. L., Chad, K. E., Spink, K. S., Muhajarine, N., Anderson, K. D., Bruner, M W., Girolami, T. M., Odnokon, P. \& Gryba, C. R. (2006). Factors that influence physical activity participation among high and low-SES youth. Qualitative Health Research, 16, 467-483.

James, K. \& Embrey, L. (2002). Adolescent girls' leisure: a conceptual framework highlighting factors that can affect girls' recreational choices. Annals of Leisure Research, 5(1), 14-26. doi: 10.1080/11745398.2002.10600896

Kirby, J., Levin, K. A. and Inchley, J. (2013). Socio-environmental influences on physical activity among young people: a qualitative study. Health Education Research, August 2013, 1-16.

Krejcie, R. V. \& Morgan, D. W. (1970). Determining sample size for research activities. Educational and Psychological Measurement, 30, 607-610.

Leech, N. L., Barrett, K. C. \& Morgan, G. A. (2011). IBM SPSS for Intermediate Statistics: Use and Interpretation (4th ed.). New York: Taylor and Francis Group, LLC.

Loukaitou-Sideris, A. \& Sideris, A. (2009). What brings children to the park? analysis and measurement of the variables affecting children's use of parks. Journal of the American Planning Association, 76(1), 89-107. doi: $10.1080 / 01944360903418338$

Mesch, G. S. (2009). The internet and youth culture. The Hedgehog Review, Spring, 5060.

Must, A. \& Tybor, D. (2005). Physical activity and sedentary behavior: a review of longitudinal studies of weight and adiposity in youth. International Journal of Obesity, 29, S84-S96.

Passon, C., Daniel L. \& Vicente d. R. (2008). Implications of adolescents' perceptions and values for planning and design. Journal of Planning Education and Research, 28(1):73-85. doi: 10.1177/0739456x08319236.

Pate, R. R, O'Neill, J. R. \& Lobelo, F. (2008). The evolving definition of "sedentary". Exerc Sport Sci Rev., 36(4). doi: 10.1097/JES.0b013e3181877d1a 
Perry, C. K., Saelens, B. E. \& Thompson, B. (2011). Rural Latino youth park use: characteristics, park amenities, and physical activity, J Community Health, 36, 389-397.

Peters, K., Elands, B. \& Buijs, A. (2010). Social interactions in urban parks: Stimulating social cohesion? Urban Forestry \& Urban Greening, 9(2), 93-100. doi http://dx.doi.org/10.1016/j.ufug.2009.11.003

Proper, K. I., Singh, A. S., van Mechelen, W. \& Chinapaw, M. J. M. (2011). Sedentary behaviors and health outcomes among adults: a systematic review of prospective studies. American Journal of Preventive Medicine, 40(2), 174-182.

Raithel, K. S. (1987). Are girls less fit than boys? The Physician and Sportsmedicine, 15(11), 157-163. doi: 10.1080/00913847.1987.11704804

Rideout, V. J., Foehr, U. G. \& Roberts, D. F. (2010). Generation M2: Media in the lives of 8- to 18-year-olds A Kaiser Family Foundation Study (Vol. January). Menlo Park, California: Henry J. Kaiser Family Foundation.

Ries, A. V., Voorhees, C. C., Roche, K. M., Gittelsohn, J., Yan, A. F. \& Astone, N. M. (2009). A quantitative examination of park characteristics related to park use and physical activity among urban youth. Journal of Adolescent Health, 45(3, Supplement), S64-S70. doi: 10.1016/j.jadohealth.2009.04.020

Ries, Amy V., Gittelsohn, Joel, Voorhees, Carolyn C., Roche, Kathleen M., Clifton, Kelly J. \& Astone, Nan M. (2008). The environment and urban adolescents' use of recreational facilities for physical activity: a qualitative study. American Journal of Health Promotion, 23(1), 43-50. doi: doi:10.4278/ajhp.07043042

Santo, C. A., Ferguson, N. \& Trippel, A. (2010). Engaging urban youth through technology: the youth neighborhood mapping initiative. Journal of Planning Education and Research, 30(1), 52-65. doi:10.1177/0739456x10366427

Saris, W. E. \& Gallhofer, I. N. (2007). Design, evaluation, and analysis of questionnaires for survey research. Hoboken, New Jersey: John Wiley \& Sons Inc.

Saunders, M., Lewis, P. \& Thornhill, A. (2009). Research methods for business students (5th ed.). Harlow, Essex: Pearson Education Limited.

Tremblay, M. S., LeBlanc, A. G, Kho, M. E., Saunders, T. J., Larouche, R., Colley, R. C., Goldfield, G. \& Gorber, S. C. (2011). Systematic review of sedentary behaviour and health indicators in school-aged children and youth. International Journal of Behavioral Nutrition and Physical Activity, 8(98), 1-22.

United Nations (2004). Rethinking Leisure Time: World Youth Report 2003. New York: The Department of Economic and Social Affairs of the United Nations Secretariat.

United Nations (2005). World Youth Report: Young People Today, and in 2015. New York: Department of Economic and Social Affairs.

United Nations Education, Scientific and Cultural Organization. (2009-2014). What do we mean by "youth"? Learning to live together. Retrieved 2 February, 2015 at http://en.unesco.org/themes/learning-live-together.

Wilson, D. K., Williams, J., Evans, A., Mixon, G. \& Rheaume, C. (2005). Brief report: a qualitative study of gender preferences and motivational factors for physical activity in underserved adolescents. Journal of Pediatric Psychology, 30(3), 293-297. doi: 10.1093/jpepsy/jsi039 
Rosilawati Zainol \& Cheong Peng Au-Yong

What Brings Youth to Recreational Parks?

World Health Organization. (2015). Obesity and overweight. Fact sheet 311. Retrieved 2 February, 2015 at http://www.who.int/mediacentre/factsheets/fs311/en/.

Zulkia, D. R., Zainol, R., Zainol, N., Nordin, N. A. \& Ahmad, F. (2014). Factors determining youth's recreational behaviour and its effects on body mass index (BMI). Journal of Surveying, Construction and Property, 5(2), 1-11. 


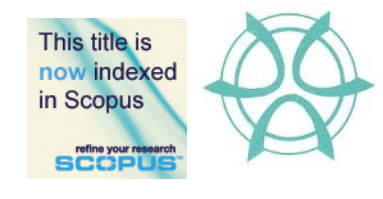

PLANNING MALAYSIA:

Journal of the Malaysian Institute of Planners

VOLUME XIV (2016), Page 81 - 94

\title{
NEIGHBOURHOOD SATISFACTION AND QOUL IN MIDDLE- INCOME HOUSING IN KUALA LUMPUR CITY, MALAYSIA
}

\author{
Mohammad Abdul Mohit ${ }^{1}$ \& Mohamed Sajid Ali ${ }^{2}$ \\ ${ }^{1}$ Kulliyyah of Architecture and Environmental Design \\ INTERNATIONAL ISLAMIC UNIVERSITY MALAYSIA \\ ${ }^{2}$ CRN RAO (PVT) LTD, CHENNAI, INDIA
}

\begin{abstract}
This paper is based on the subjective perception of the residents about the neighbourhood environment and their quality of urban life. The neighbourhood satisfaction provides a generalized view into the well-being of the residents, and it has been viewed as a significant aspect of the quality of urban life (QOUL). As a contributor to life satisfaction, neighbourhood satisfaction is influenced by individual and household socio-economic variables, along with the neighbourhood characteristics. However, there is limited understanding of how neighbourhood environments influence neighbourhood satisfaction and the quality of urban life. This paper intends to examine the relationship between residents' neighbourhood satisfaction and their quality of urban life in a middleincome housing area in Kuala Lumpur City, Malaysia, by using 100 sample respondents that fulfilled a confidence level of $90 \%$ of the population. The findings of the study indicate that the residents are satisfied with their existing QOUL, but if no actions are taken it will deteriorate. Therefore, several recommendations are made for improving the residents' QOUL.
\end{abstract}

Keyword: Neighbourhood satisfaction, Quality of Urban Life (QOUL); Middleincome housing; Socio-economic variables. 
Mohammad Abdul Mohit \& Mohamed Sajid Ali

Neighbourhood Satisfaction and Qoul in Middle- Income Housing in Kuala Lumpur City, Malaysia

\section{INTRODUCTION}

Malaysian economy has grown steadily in the past three decades transforming the country into a middle-income nation from an agriculture and commoditybased economy. The per capita GDP has increased significantly, and the urban population in the country has increased from $25 \%$ in 1960 to $72 \%$ in 2010 . It is projected that $86 \%$ of the population will be urbanised by 2050 (United Nations, 2012). The rapid urban growth has led to a significant pressure on local and state governments on providing urban infrastructures that are intended to improve the quality of urban life. The Malaysian Quality of Life Index (MQLI) has been developed in 1999 by the Economic Planning Unit (EPU) with eleven components. Although the overall MQLI has increased by 7.0 points during 1990 to 2000 and further to another 11.9 points from 2000 to 2010 , there exists a regional variation among different states with the Federal Territory of Kuala Lumpur having the highest quality of life index (Mohit, 2013b). This achievement of Kuala Lumpur can be attributed to it being the national capital and the vision of the City plan 2020 to be "a world class city" in which good quality of life is emphasised. Most studies of quality of life (QOL) in Malaysia present subjective analysis and there is a lack of literature that could explain the relationship between the neighbourhood satisfaction and quality of urban life (QOUL) in different housing areas of Kuala Lumpur City. Therefore, this paper intends to examine the relationship between neighbourhood satisfaction and QOUL in terrace housing through a case study in Kuala Lumpur City, Malaysia.

\section{OBJECTIVES}

The aim of the study is to determine the relationship between neighbourhood satisfaction and quality of urban life through the following objectives:

a. To investigate the level of satisfaction of the residents about the neighbourhood and quality of urban life.

b. To explore the relationship between neighbourhood satisfaction and quality of urban life.

c. To identify the key determinants of neighbourhood satisfaction and quality of urban life.

d. To suggest measures towards improving the neighbourhood satisfaction level and hence, the quality of urban life.

\section{LITERATURE REVIEW}

\section{Quality of Life (QOL) and Quality of Urban Life (QOUL)}

Quality of life (QOL) refers to 'goodness of life' and being able to live successfully and happily within the environment. There is neither a universal definition nor a standard form of measurement for quality of life, and this has made studying it more challenging and interesting for researchers (Cummins, 
PLANNING MALAYSIA

Journal of the Malaysian Institute of Planners (2016)

1997). Different people in different parts of the world have defined QOL differently based on their cultures, social environment and level of economic development (Mohit, 2013a).

In spite of this, World Health Organization (WHO) has prepared a crossculturally comparable quality of life assessment instrument called WHOQOL$\mathrm{BREF}$, and defines QOL as-

"An individual's perception of his/her position in the context of culture and value systems in which they live in and in relation to their goals, expectations, standards and concerns. It is a broad ranging concept incorporating in a complex way, the person's physical health, psychological state, level of independence, social relationships, personal beliefs and relationships to salient features of the environment" (WHOQOLGroup, 1998).

As the world is becoming rapidly urbanised, it is estimated that more and more people will be living in urban areas. As the urban population grows, maintaining the quality of life in the urban areas becomes more difficult, and it becomes a matter of concern. Therefore, studies on quality of life in urban areas become a necessity as QOL can -

a) Provide the necessity for public action (Dahmann, 1985), (Lu, 1999);

b) Affect the liveability of urban areas and provide a set of indicators that help policy makers and planners to assess the effectiveness of their policies (Marans, 2012);

c) Impact the choice for residential location in the city (Golledge \& Stimson, 1987); and

d) On a broader scale affect the patterns of regional migration, economic growth, and environmental sustainability (Kemp et al., 1997).

In the 1980s, the perception of QOL was becoming imperative in studies focusing on the quality of a place or the geographic setting at various scales (country, city, community and neighbourhood). These kinds of studies referred to as quality of urban life (QOUL) dealt mainly with assisting urban policy development and resource allocation to urban needs (Marans, 2012). This focus is conceptually distinct from individual QOL research that has examined factors impacting individual's well-being. Thus, the concept of the quality of life is divided into two distinct types - (a) Individual QOL that includes family life, friends, partner satisfaction, and (b) Environmental QOL which involve the quality of urban life that interest the environment behaviour researchers. The second group ranged in scale from the individual dwelling, community, neighbourhood, city, region, or even to the state or nation. It has been remarked 
Mohammad Abdul Mohit \& Mohamed Sajid Ali

Neighbourhood Satisfaction and Qoul in Middle- Income Housing in Kuala Lumpur City, Malaysia

that where people live, will influence their lives and, therefore, their overall QOL (Marans \& Stimson, 2011).

\section{Neighbourhood Satisfaction and Quality of Life}

The concept of neighbourhood satisfaction is very much linked with the quality of life studies (Sirgy \& Cornwell, 2002). Researchers often use these two terms interchangeably. The neighbourhood satisfaction and quality of life ultimately measure different aspects, both of which are important to urban planners and policy makers. Morris and Winter (1978) pointed out that a family evaluates a neighbourhood based on the following normative criteria: (a) the area should be predominately residential; (b) it should be accessible to quality schools; (c) the area should have quality of streets and roads; and (d) it should have homogeneity regarding social class, race, and ethnic group. Thus, Lu (1999) contends that neighbourhood satisfaction has been shown to be an important predictor of housing satisfaction. Residential satisfaction does not only rely on the dwelling units itself; neighbourhood plays an important role in residential satisfaction (Nurizan \& Hisham, 2001; Salleh, 2012).

Studies have found that neighbourhood dissatisfaction, however, occurs about distances travelled to school by children, to employment and medical centres and the geographical location of housing estates. Also accessibility to the public transportation, community and shopping facilities and physical environment variables were identified as predictors of neighbourhood satisfaction. Another author has thus observed that location characteristics are important considerations for understanding the formation of residential satisfaction among public housing tenants. While housing is likely to be a source of satisfaction, neighbourhood conditions such as level of crime (Mulligan et al., 2004) or lack of amenity or industrial development or workplace location, are likely to be the sources of neighbourhood dissatisfaction. Alison, et al. (2002) contend that although socio-demographic factors were much less important than residents' perceptions in helping to predict neighbourhood dissatisfaction, the type of neighbourhood remained a significant independent predictor of dissatisfaction even when the residents' views were taken into account.

Yancy (1971), in a study of Pruitt-Igo, St. Louis, remarked that the main reason for the failure of Pruitt-Igo, was the lack of neighbourhood cohesion and social order associated with the dissatisfaction of the neighbours. Djebarni and Al-Abed (2000), in their study of public low-income housing in Sana'a, Yemen, found that the residents attach great importance to the level of satisfaction with their neighbourhood, particularly with the privacy that reflects the cultural background of Yemeni society.

The neighbourhood satisfaction reflects residents' complex evaluations about how well a neighbourhood meets their physical and social needs (Galster \& Hesser, 1981). Quality of life is more holistic taking into consideration overall 
PLANNING MALAYSIA

Journal of the Malaysian Institute of Planners (2016)

well-being, rather than actual conditions of the neighbourhood itself. The neighbourhood quality of life can be conceptualized as aspects of the residents' living situation that enable them to feel better, maintain independence, and physically, mentally, and socially improved (Fisher \& Fuzhong, 2004). Assessing quality of life from neighbourhood satisfaction has been studied by Oktay and Ahmet (2011) in the walled city of Famagusta. There are different methods by which the relationship between neighbourhood satisfaction and quality of life can be established. For example, Sirgy \& Cornwell (2002) tested three hypotheses while trying to find a relationship between the two.

Studies on the relationship between neighbourhood satisfaction and life satisfaction presents mixed findings. Oktay et al (2009) found no relationship between neighbourhood satisfaction and the QOUL in the walled city of Famagusta, North Cyprus. On the contrary, Sirgy and Cornwell (2002) analysed three models to examine the relationship between neighbourhood satisfaction and life satisfaction, and found that the relationship is positive through some mediating variables. In Dhaka, Bangladesh, it was found that the overall sociophysical features of the neighbourhood and community influence life satisfaction more than the physical features of the individual dwelling (Mridha \& Moore, 2011). Sedaghatnia et.al (2013) studied the QOL and neighbourhood satisfaction in a mixed use high density neighbourhood in Kuala Lumpur city centre, and found that $68 \%$ of the residents were satisfied with the overall QOL while $32 \%$ were not.

The foregoing review of empirical studies about the relationship between neighbourhood satisfaction and QOL indicates that there are mixed findings. Therefore, there are opportunities for further research towards investigating the relationship between neighbourhood satisfaction and QOL that can be pursued by housing types, tenures, countries and cultures and that further research are required to determine QOUL on case-specific context to guide the directions of housing and urban public policies (Mohit, 2014).

\section{METHODOLOGY}

Methodology is a systematic approach adopted to explain about the research design, sampling frame, techniques of data collection and analysis.

\section{Research Design and Sampling Frame}

The main purpose of the study is to examine the relationship between neighbourhood satisfaction and quality of urban life. Hence, satisfaction levels of the respondents about the physical, social and economic conditions of the neighbourhood were measured along with satisfaction levels of the home, the neighbourhood and the QOUL. These levels are obtained through the primary data collected through a questionnaire survey. The research was carried out based on the subjective perception of the residents about the neighbourhood 
Mohammad Abdul Mohit \& Mohamed Sajid Ali

Neighbourhood Satisfaction and Qoul in Middle- Income Housing in Kuala Lumpur City, Malaysia

environment and the quality of life. For measuring the satisfaction levels, a fivepoint Likert-scale with ' $1=$ very unsatisfied... $5=$ very satisfied', was used. Based on the literature review, three types of variables -dependent, independent, and control, were used in the research design. The dependent variables are overall satisfaction levels. The independent variables are the physical, social and the economic conditions of the neighbourhood. The control variables are the demographic and socio-economic characteristics of the respondents.

By using a confidence level of $90 \%$, the sample (n) required for a population of 4725 ( $\mathrm{N}=$ Study area population) was 99, but we used 100 respondents/ residents for survey. Due to time and budget constraints, it was not possible to increase the sample size. This is one of the limitations of the study.

Many researchers have argued that, the quality of any entity has a subjective dimension that is perceptual as well as having an objective reality. Therefore, both objective and subjective components of QOL are necessary to provide an understanding of it (Marans, 2012). Hence, in this study, assessment of residents' quality of life was done through their subjective well-being as it is closely related to the ways residents perceive or evaluate their neighbourhood condition to achieve life satisfaction.

\section{Data Collection}

Two types of data - primary and secondary were collected for this study. The primary data was obtained through observation, interview and questionnaire survey. A questionnaire was developed with five sections. Section-1 contained the demographic and socio-economic characteristics of the respondents. Section2 was about the satisfaction with the physical features/ conditions of the neighbourhood. Section-3 was about the satisfaction with the social conditions of the neighbourhood. Section-4 was about the satisfaction with the economic conditions of the neighbourhood. Section-5 contained three questions, viz., their house, neighbourhood and QOUL. A total of 110 questionnaires were used for the survey, but ten questionnaires were rejected as they contained defective responses. The survey was carried out during weekends for two months i.e. December 2012 and January 2013.

\section{Data Analysis}

Both descriptive and inferential statistics were used for data analysis. Socio demographic characteristics of the respondents were analysed through descriptive statistics. The mean satisfaction levels of the physical, social and economic conditions of the neighbourhood, home, overall neighbourhood and QOUL were analysed through descriptive statistics. Correlation analysis was employed to find an association between the variables and the satisfactions. AMOS version of Structural Equation Modelling (SEM) was employed to find out the determinants of neighbourhood satisfaction and QOUL. 
PLANNING MALAYSIA

Journal of the Malaysian Institute of Planners (2016)

\section{Study Area and Limitations of the Study}

The housing area selected for study is Setiawangsa - an eastern suburb of Kuala Lumpur City that is located less than 4 kilometres from the city centre. The study was carried out in one type of housing, i.e., the middle-income terrace housing. Because of time and resource constraints, the study was limited to 100 samples from a population of 4725 middle-income families. However, the study cannot be used to generalise the phenomenon. For generalization, further studies in different parts of the city and covering other types of houses are required.

\section{FINDINGS AND ANALYSIS}

\section{Socio-Economic and Demographic Characteristics}

The majority of the respondents (84\%) were male and a majority of them (56\%) were between 21 to 50 years of age followed by $26 \%$ who were in the age group of 51-60 years. Only 5\% of the respondents were more than 60 years. Whereas $60 \%$ of the respondents were married, $37 \%$ of the respondents were single/unmarried with $3 \%$ who were widowed/divorced. $84 \%$ of the respondents were Malays followed by $8 \%$ Indian, 3\% Chinese, and $5 \%$ of other races. Whereas $62 \%$ of the respondents were Graduates/Diploma holders, $18 \%$ completed SPM (O' level) followed by $13 \%$ who had postgraduate degrees. $3 \%$ of the respondents completed STPM (A' level) while another 3\% completed $\mathrm{Ph}$.D. degree, and only $1 \%$ had other educational qualifications.

The majority $(34 \%)$ of the respondents were in others job category, followed by $32 \%$ professional/technical job holders and $15 \%$ occupied managerial/administrative positions while $12 \%$ were involved in business. The mean household size was 5.4. The mean earning members in the household is 2.5 . While $73 \%$ of the respondents had more than RM5000 as monthly household income, $11 \%$ reported having monthly household income of RM3001 - RM4000. The rest $26 \%$ had income below RM3000. The majority of the respondents (84\%) were house owners and $16 \%$ were renters. Also, $91 \%$ of the respondents owned at least one car while only $9 \%$ did not own a car. The mean age of respondents' houses is 16.8 years. The mean residency is 12.8 years.

\section{Satisfaction with the Physical Conditions of the Neighbourhood}

Residents' satisfaction with the physical conditions of the neighbourhood shows that the mean satisfaction score (MSS) of most of the neighbourhood physical features are below the overall MSS of 3.7, with the exceptions of nearness of neighbourhood to facilities (MSS=4.6) and the accessibility to public transport (MSS=4.1). Upkeep of the housing area and urban design/aesthetics of the neighbourhood has MSS of 3.7 each, indicating a moderate level of satisfaction. Landscape/greenery, street lighting in the neighbourhood and noise level have similar MSS of 3.6 which indicates that residents are "moderately satisfied". 
Mohammad Abdul Mohit \& Mohamed Sajid Ali

Neighbourhood Satisfaction and Qoul in Middle- Income Housing in Kuala Lumpur City, Malaysia

Finally, the satisfaction level for crowding in the neighbourhood is also at moderate level with a mean of 3.5. The correlation coefficients $(r)$ show that except the variable of noise level, all seven variables representing physical conditions of the neighbourhood, have significant positive correlations with satisfactions with overall neighbourhood physical conditions.

\section{Satisfaction with the Social Conditions of the Neighbourhood}

Residents' satisfaction with the social features and conditions of the neighbourhood shows that the MSS with the overall social condition is $3.7-$ slightly over a moderate level. Respondents rated a high score of satisfaction on privacy at home (MSS=4.00), followed by the neighbourhood cohesion and race relations in the community, in which the MSSs are 3.8 each. Social interaction with neighbours and ties with people in the community, both have the same MSS of 3.7, while the MSS for outdoor play spaces/open spaces of the neighbourhood is 3.6. Respondents revealed relatively lower satisfaction levels with crime (MSS=3.3) and safety (MSS=3.5) in the neighbourhood. The variables of the component have significant positive correlations $(r)$ with satisfaction with neighbourhood social condition. However, safety, race relations, people living, and open spaces, have higher $(r)$ values than the other variables in the component.

\section{Satisfaction with the Economic Conditions of the Neighbourhood}

Residents' satisfaction with economic conditions of the neighbourhood shows that the MSS for the overall economic conditions is 3.7 - slightly above the moderate level. MSS with the value of the house has a mean of 4.00 which indicates a high level of satisfaction. Respondents' MSS to all other economic indicators of the neighbourhood like socio-economic status, neighbourhood improvement/ development and the cost of living, are at moderate level with MSS ranging from 3.5 to 3.7. The correlation coefficients $(r)$ show that all the variables have significant positive correlations with the component. However, improvement, management, socio-economic status and value of the house, have higher correlations with the component compared with cost of living.

\section{Residents' Satisfaction with the Home, Neighbourhood and the QOUL}

The analysis of the respondents' satisfaction about the home, neighbourhood and QOUL (Table 1) shows that the residents are very satisfied with their homes (MSS=4.2), followed by their neighbourhood (MSS=4.00). The satisfaction with the overall quality of urban life is the lowest among the three with an MSS of 3.8. Hence, they are between "slightly satisfied to satisfied" for this parameter. 
Table 1. Distribution of residents' satisfaction with QOUL

\begin{tabular}{|c|c|c|c|c|c|c|c|c|}
\hline $\begin{array}{l}\text { Satisfaction } \\
\text { with }\end{array}$ & 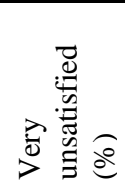 & 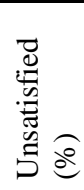 & 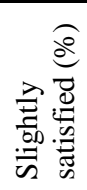 & 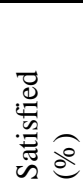 & 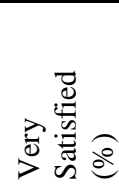 & $\stackrel{\Xi}{\Sigma}$ & $\stackrel{\theta}{i s}$ & 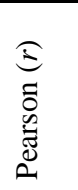 \\
\hline The home & - & 1 & 12 & 50 & 37 & 4.2 & 0.7 & $.42 * *$ \\
\hline $\begin{array}{l}\text { Neighbour- } \\
\text { hood }\end{array}$ & 1 & - & 21 & 55 & 23 & 4.0 & 0.7 & $.40 * *$ \\
\hline QOUL & - & 5 & 22 & 61 & 12 & 3.8 & 0.7 & 1.00 \\
\hline
\end{tabular}

Source: Field Survey, 2012-13.

Note: **Significant at 0.01 level (2-tail).

\section{STRUCTURAL EQUATION MODELING (SEM)}

Structural equation modelling uses confirmatory factor analysis. It is hypothesised that QOUL depends on the satisfaction with neighbourhood which in turn is dependent on the satisfactions of various physical, social and economic conditions of the neighbourhood. The model is "Fit" since the minimum is achieved. The variables were classified into two types based on the hypothesis as observed endogenous variables and observed exogenous variables. Observed endogenous variables are the dependent variables, and these are - satisfaction with physical neighbourhood features, satisfaction with neighbourhood social conditions, satisfaction with neighbourhood economic conditions, satisfaction with neighbourhood and satisfaction with QOUL.

The regression weights obtained from the path analysis in the model (Table 2) shows that the satisfaction score of the neighbourhood physical features is highly dependent upon the urban design/aesthetics of the neighbourhood with a value of 0.40 , followed by the variable of nearness to facilities having a value of 0.21 . Lower regression weights ranging from .03 to 0.15 were obtained with street lighting, landscape/greenery, Upkeep of the housing area, and crowding in the neighbourhood. The remaining two factors - access to public transport and noise level in the neighbourhood have the negative effect upon physical features of the neighbourhood.

Sense of safety in the neighbourhood having a regression weight of 0.41 is the most important factor for satisfaction with social conditions of the neighbourhood. The next variable is community cohesion in the neighbourhood with a regression weight of 0.18 followed by race relations with a regression value of 0.16 . Lower regression weights ranging from .04 to 0.16 were obtained with open spaces, sense of privacy at home, and ties with the people in the community. The other two variables - social interaction with neighbours and crime level in the community, have negative weights. 
Mohammad Abdul Mohit \& Mohamed Sajid Ali

Neighbourhood Satisfaction and Qoul in Middle- Income Housing in Kuala Lumpur City, Malaysia

Satisfaction with economic conditions of the neighbourhood is most affected by neighbourhood developments/improvements with a regression weight of 0.33. Socio-economic status and management/maintenance of the neighbourhood has a regression weight of 0.22 . The value of the house in the neighbourhood has a regression weight of 0.05 . The only factor which has a negative value (-0.01) is the cost of living in the neighbourhood.

Among the three factors - satisfactions with physical, social and economic conditions of the neighbourhood, satisfaction with the economic conditions of the neighbourhood with a regression weight of 0.32 , affects most the satisfaction with the neighbourhood. This is followed by the satisfaction with the physical features with a value of 0.30 . The least regression weight $(0.07)$ is by the satisfaction with the social conditions of the neighbourhood. However, all three factors have positive effects on the satisfaction with the neighbourhood. Satisfaction with the overall quality of urban life is influenced positively with a regression weight 0.39 by overall neighbourhood satisfaction. 
PLANNING MALAYSIA

Journal of the Malaysian Institute of Planners (2016)

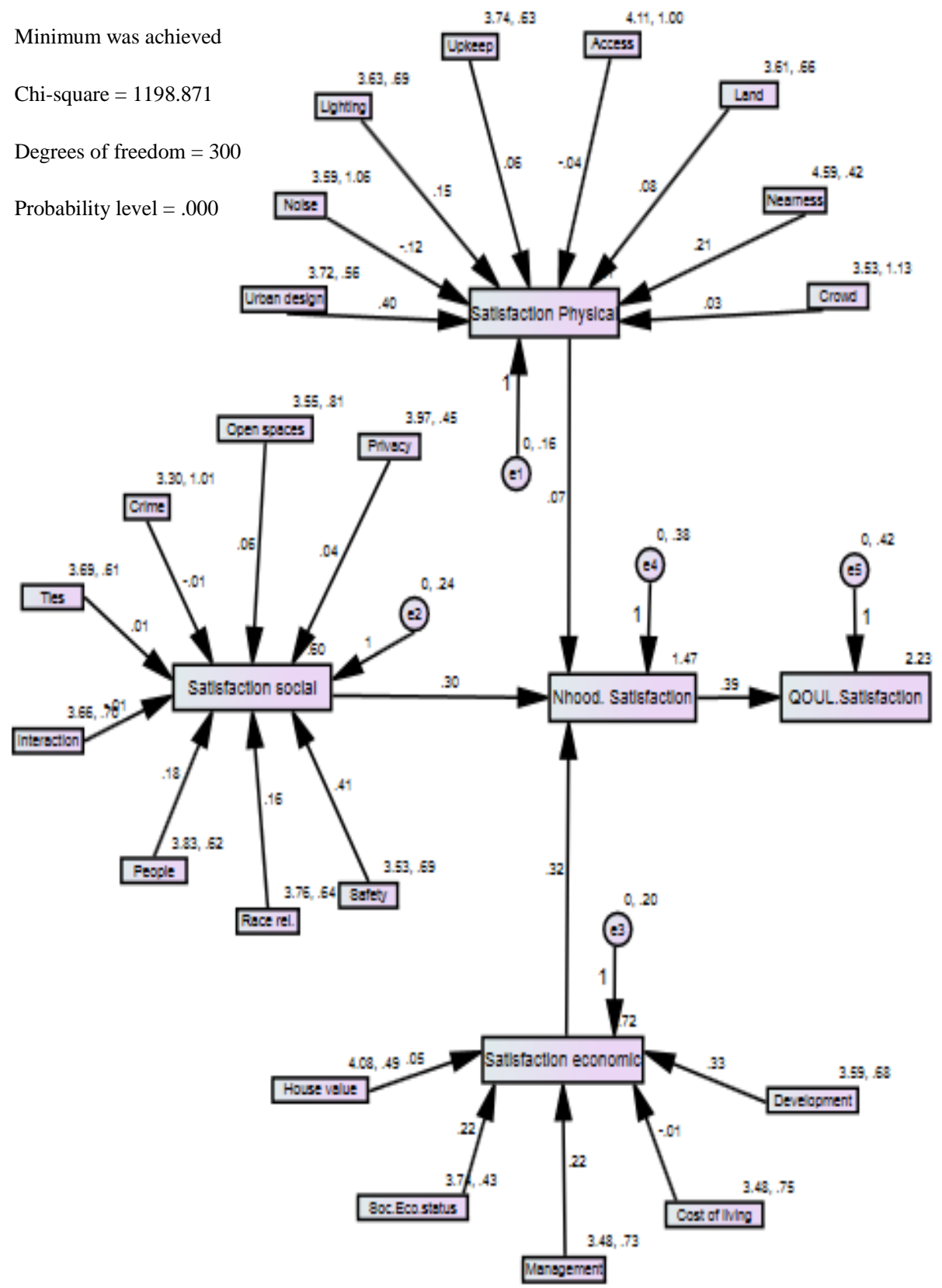

Figure 1 Structural Equation Model

Source: Data analysis 
Mohammad Abdul Mohit \& Mohamed Sajid Ali

Neighbourhood Satisfaction and Qoul in Middle- Income Housing in Kuala Lumpur City, Malaysia

Table 2: Regression weights obtained from path analysis of SEM

\begin{tabular}{|c|c|c|c|c|c|c|}
\hline & & & $\begin{array}{c}\text { Estim } \\
\text { ate }\end{array}$ & S.E. & C.R. & $p$ \\
\hline SOC.CONDITIONS & $<--$ & PRIVACY & .04 & .07 & .54 & .59 \\
\hline SOC.CONDITIONS & $<---$ & INTERACTION & -.01 & .06 & -.21 & .84 \\
\hline SOC.CONDITIONS & $<---$ & TIES & .01 & .06 & .09 & .93 \\
\hline SOC.CONDITIONS & $<---$ & OPENSPACES & .06 & .05 & 1.14 & .25 \\
\hline SOC.CONDITIONS & $<---$ & SAFETY & .41 & .06 & 6.96 & $* * *$ \\
\hline SOC.CONDITIONS & $<--$ & CRIMELEVEL & -.01 & .05 & -.12 & .90 \\
\hline SOC.CONDITIONS & $<--$ & COM.COHESION & .18 & .06 & 2.94 & .00 \\
\hline SOC.CONDITIONS & $<---$ & RACERELATIONS & .16 & .06 & 2.65 & .01 \\
\hline ECO.CONDITIONS & $<---$ & MANAGEMENT & .22 & .05 & 4.22 & $* * *$ \\
\hline ECO.CONDITIONS & $<---$ & HOUSEVALUE & .05 & .06 & .75 & .45 \\
\hline PHY.FEATURES & $<--$ & CROWDING & .03 & .04 & .83 & .40 \\
\hline PHY.FEATURES & $<--$ & NEARNESS & .21 & .06 & 3.40 & $* * *$ \\
\hline PHY.FEATURES & $<--$ & UPKEEP & .06 & .05 & 1.15 & .25 \\
\hline PHY.FEATURES & $<---$ & PUB.TRANS & -.04 & .04 & -.92 & .36 \\
\hline PHY.FEATURES & $<---$ & URBANDESIGN & .40 & .05 & 7.30 & $* * *$ \\
\hline PHY.FEATURES & $<---$ & NOISE & -.12 & .04 & -2.94 & .00 \\
\hline PHY.FEATURES & $<---$ & LANDSCAPE & .08 & .05 & 1.66 & .10 \\
\hline PHY.FEATURES & $<---$ & LIGHTING & .15 & .05 & 3.12 & .00 \\
\hline ECO.CONDITIONS & $<---$ & DEVELOPMENT & .33 & .05 & 6.21 & $* * *$ \\
\hline ECO.CONDITIONS & $<---$ & COSTOFLIVING & -.01 & .05 & -.17 & .87 \\
\hline ECO.CONDITIONS & $<---$ & SOC.ECO.STATUS & .22 & .07 & 3.19 & .00 \\
\hline NHOOD.SATISFACTION & $<---$ & SOC.CONDITIONS & .30 & .10 & 2.97 & .00 \\
\hline NHOOD.SATISFACTION & $<---$ & PHY.FEATURES & .07 & .11 & .62 & .53 \\
\hline NHOOD.SATISFACTION & $<---$ & ECO.CONDITIONS & .32 & .11 & 2.92 & .00 \\
\hline QOUL.SATISFACTION & $<---$ & $\begin{array}{l}\text { NHOOD.SATISFACT } \\
\text { ION }\end{array}$ & .39 & .10 & 4.06 & $* * *$ \\
\hline
\end{tabular}

S.E = Standard Error, C.R $=$ Critical Ratio, $p=$ Probability

Source: Field Survey, 2012-13.

\section{CONCLUSION AND RECOMMENDATION}

As a contributor to life satisfaction, neighbourhood satisfaction is influenced by individual and household socio-economic variables, along with neighbourhood characteristics. The study found that among the three neighbourhood factors satisfactions with physical, social and economic conditions, satisfaction with the economic conditions are highly correlated, followed by the physical conditions with the neighbourhood satisfaction. The least effect is by satisfaction with the social conditions of the neighbourhood. But all three factors have positive effects on the satisfaction with the neighbourhood. Satisfaction with the overall quality of urban life is influenced positively by the overall satisfaction with the neighbourhood.

Although, for most of the factors, the respondents are very satisfied, there are some factors for which their satisfaction level is low. So the following recommendations are made for improving them. 
a. Density of people in new residential developments should reduce crowding with which the residents are found just satisfied.

b. More surveillance measures should be undertaken to reduce crime and enhance neighbourhood safety to enhance residents' satisfaction with them.

c. The management/ maintenance of the neighbourhood should be improved to enhance neighbourhood satisfaction and QOUL.

d. Finally, public participation and consultation must be undertaken by the authorities for future planning and development.

Overall, the residents were moderately satisfied with the existing QOUL. But if no further actions are taken, it may deteriorate. So the following recommendations are made for improving the QOUL.

a. Since the relationship between QOUL and neighbourhood is established from the findings, steps to improve the neighbourhood satisfaction must be undertaken by the local authorities.

b. Assessments of QOUL should be made from time to time by the local authorities as the needs of people might change with time.

c. Since economic factors are vital to affect QOUL compared to other factors, the government should take necessary measures to improve the economic conditions of residents so the overall quality of life of the people in general can improve.

\section{REFERENCES}

Alison, P., Kearns, A. \& Atkinson, R. (2002). What makes people dissatisfied with their neighbourhoods? Urban Studies, 39(13), 2413-2438.

Cummins, R. A. (1997). Comprehensive Quality of Life Scale: Manual. Melbourne: Deakin University.

Dahmann, D. C. (1985). Assessments of neighborhood quality in metropolitan America. Urban Affairs Quarterly, 20(4), 511-535.

Djebarni, R. \& Al-Abed, A. (2000). Satisfaction level with neighbourhood in low-income public housing in Yemen. Property Management, 18(4), 230-242.

EPU (2012). The Malaysian quality of life index 2011. Putrajaya: EPU, Prime Minister's Department.

Fisher, K. \& Fuzhong, L. (2004). A Community-based walking trail to improve neighborhood quality of life in older adults: a multilevel analysis. Annals of Behavioral Medicine , 28 (3), 186-94.

Galster, G. C. \& Hesser, G. (1981). Residential satisfaction: compositional and contextual correlates. Environment and Behavior, 13(6), 735-758.

Golledge, R. G. \& Stimson, R. J. (1987). Analytical Behavioural Geography. London: Croom Helm.

Kemp, D., Manicaros, M., Mullins, P., Simpson, R., Stimson, R. \& Western, J. (1997). Urban Metabolism: A Framework for Evaluating the Viability, Livability and 
Mohammad Abdul Mohit \& Mohamed Sajid Ali

Neighbourhood Satisfaction and Qoul in Middle- Income Housing in Kuala Lumpur City, Malaysia

Sustainability of South East Queensland. Brisbane: The Australian Housing and Urban Research Institute.

Lu, M. (1999). Determinants of residential satisfaction: Ordered logit vs. regression models. Growth and Change, 30(Spring), 264-287.

Marans, R. (2012). Quality of urban life studies: an overview and implications for environment-behavior research. Procedia-Social and Behavioural Sciences, 35, 9-22.

Marans, R. \& Stimson, R. (2011). Investigating Quality of Urban Life: Theory, Methods, and Empirical Research (Social Indicators Research Series 45 ed.). London: New York: Springer Science+Business Media.

Mohit, M.A. (2014). Present trends and future directions of quality of life. Procedia Social and Behavioral Sciences, 153, 655-665.

Mohit, M.A. (2013a). Quality of life in natural and built environment - an introductory Analysis.Procedia - Social and Behavioral Sciences, 101, 33-43.

Mohit, M.A. (2013b). Objective analysis of variation in the regional quality of life in malaysia and its policy implications. Procedia - Social and Behavioral Sciences, 101, 454-464.

Morris, E.W. \& Winter, M. (1978). Housing, Family and Society. New York: Wiley.

Mridha \& Moore (2011). The QOL in Dhaka, Bangladesh: Neighbourhood qualty as a major component in residential satisfaction. In R. Marans \& R. Stimson (Eds.), Investigating Quality of Urban Life: Theory, Methods, and Empirical Research. Social Indicators Research Series 45, (251-272). Springer Science+Business Media.

Mulligan, G., Carruthers, J. \& Cahill, M. (2004). Urban quality of life and public policy: A survey. In R. Capello \& P. Nijkamp (Eds.), Advances in urban economics (729-802). Amsterdam: Elsevier Science B.

Oktay, D. \& Ahmet, R. (2011). The quality of urban life and neighborhood satisfaction in Famagusta, Northern Cyprus. In R. Marans, \& R. Stimson (Eds.), Investigating Quality of Urban Life: Theory, Methods, and Empirical Research. Social Indicators Research Series 45, (233-249). Springer Science+Business Media

Salleh, A. (2012). Sustainable urban neighborhoods: the need to consider residents ${ }^{\text {ee }}$ satisfaction. OIDA International Journal of Sustainable Development , 3(10), 103-108

Sedaghatnia, S., Lamit, H., Ghahramanpouri, A. \& Mohamad, S. (2013). An Evaluation of residents' quality of life through neighbourhood satisfaction in Malaysia. Environmental Management and Sustainable Development, 2(1), 114-125.

Sirgy, M. \& Cornwell, T. (2002). How neighborhood features affect quality of life. Social Indicators Research, 59, 79-114.

United Nations (2012). World Urbanization Prospects, the 2011 Revision. New York: United Nations.

WHOQOLGroup (1998). The world health organization quality of life assessment(WHOQOL): development and general psychometric properties. Social Science and Medicine , 46(12), 1569-85.

Yancy, W. (1971). Architecture, interaction and social control. Environment and Behavior, 3, 3-18. 

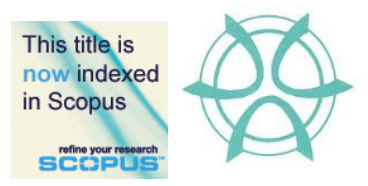

PLANNING MALAYSIA:

Journal of the Malaysian Institute of Planners

VOLUME XIV (2016), Page 95 - 106

\title{
IDENTIFYING FACTORS INFLUENCING URBAN SPATIAL GROWTH FOR THE GEORGE TOWN CONURBATION
}

\author{
Mohd Amirul Mahamud ${ }^{1}$, Narimah Samat ${ }^{2} \&$ Norzailawati Mohd Noor ${ }^{3}$ \\ ${ }^{1 \& 2}$ School of Humanities \\ UNIVERSITI SAINS MALAYSIA \\ ${ }^{3}$ Kulliyyah of Architecture and Environmental Design \\ INTERNATIONAL ISLAMIC UNIVERSITY MALAYSIA
}

\begin{abstract}
Urban growth, which caused spatial land use and land cover changes has affected various physical environment, social, and economic activities. Thus, in order to understand the dynamic process of urban spatial growth, researchers throughout the world have implemented diverse approaches, where spatial models have been developed to predict and simulate future urban growth. Those models were developed based on the driving forces that stimulate urban spatial growth. Therefore, in ensuring reliable models to be developed will be able to forecast future changes and their potential environmental effects, the driving forces must be identified. The objective of this paper is to identify possible driving forces that promote urban spatial growth of the George Town Conurbation. The study was conducted based on reviewing recent publications in journals and an on-line survey. An on-line survey was generated and distributed to academicians and urban planners to identify factors influencing urban spatial growth and their weights. The findings indicated that distance to public amenities, cheap housing price, and distance to the workplace are among factors that are important determinants of urban development. The results provide valuable insights in modelling urban growth in future research.
\end{abstract}

Keyword: Urban Spatial Growth, Driving Forces, George Town Conurbation 
Mohd Amirul Mahamud, Narimah Samat \& Norzailawati Mohd Noor

Identifying Factors Influencing Urban Spatial Growth for The George Town Conurbation

\section{INTRODUCTION}

Urbanisation is among the most significant process that has shaped land use activities and has drawn a great deal of attention throughout the world. It is estimated that urban population will rise from 3.57 billion in 2010 to 6.34 billion in 2050 where almost 70 percent of the world's population is expected to live in the cities (United Nations, 2014). This immense figure is mainly due to migration from rural to city in search of better quality of life generated by urban activities and services (Deng, Wang, Hong \& Qi, 2009).

However, an increase of urban population has forced cities to expand vertically or horizontally, encroaching into agricultural land and natural boundaries, and changing land use and land cover without us realizing it $(\mathrm{Su}$, Jiang, Zhang \& Zhang, 2011). The George Town Conurbation is no exception as exemplified by the two revisions made by Federal Department of Town and Country Planning (FDTCP, 2015a) on George Town Conurbation's boundaries due to rapid urbanisation caused by George Town city. Deeper understanding of the concepts or mechanisms underlying the urban growth can assist toward formulating appropriate policies of urban growth management, and thus, lessening the negative impacts of urbanisation while maximising the positive impacts (Aguayo, Wiegand, Azócar, Wiegand \& Vega, 2007).

In understanding urban growth and development, spatial model has been developed and implemented (Batty, 1971; Briassoulis, 2008). These models have the ability to simulate the spatial changes of land use and land cover of a city and forecast the possible urban development according to data received (Hu \& Lo, 2007). In order to develop reliable models that can be used in forecasting urban change, various factors or driving forces that stimulate urban change in a very complex manner needs to be considered (Deng et. al., 2009). Thus, determining and studying the factors or driving forces that stimulate urban growth is the fundamental step in the development of such model (Verburg, Schot, Dijst \& Veldkamp, 2004; Briassoulis, 2008).

Aguayo et. al. (2007) emphasise that the factors that stimulate urban development, especially those factors that can be used to predict future changes and their potential environmental effects must be identified and analysed in order to understand the spatial and temporal dynamics of these processes. However, this may be difficult since various stakeholders and expert opinion need to be considered. Multi Criteria Evaluation Approach (MCE) can potentially be used since this approach allows various choice possibilities and criteria to be considered in decision making (Malczewski, 1999). Therefore, the objective of this paper is to identify and analyse possible driving forces that promote urban spatial growth in the context of urban growth in Malaysia, which will then be included in modelling the George Town Conurbation spatial growth. 
PLANNING MALAYSIA

Journal of the Malaysian Institute of Planners (2016)

\section{BACKGROUND OF THE STUDY}

To date, various studies that identify and utilise driving forces urban growth model have been conducted throughout the world (Lo \& Yang, 2002; Aguayo et. al., 2007). For example, Aguayo et. al. (2007) revealed that urban growth areas are stimulated by distance and density of specific elements which implies proximity and neighbourhood are two important driving forces to urban development. It is difficult to develop an area if the road network is not well constructed because roads open many opportunities, especially for business by attracting higher population migration. Residents' desire to live at a location with easy access to other destinations helps to explain the construction of nodes and highways in many urban areas. Road network not only facilitates residents' daily lives but also reduces construction cost for amenities like shopping malls and hospitals (Li, Zhou \& Ouyang, 2013).

Industrialisation or commercialisation which implies economic factor is also one of the important determinants in promoting urban development $(\mathrm{Lu}, \mathrm{Wu}$, Shen \& Wang, 2013; Liu, Wang \& Long, 2008; Lo \& Yang, 2002). It offers many job opportunities which attract employees to stay in the vicinity and also influences road network development to stimulate economic factor in regional trade (Lu et. al., 2013). Lo and Yang (2002), for example, found that industrial and commercial activities are located at high-density urban area, which proved that these two activities are also important forces in developing an area. The increase of investment in secondary and tertiary industries has boosted land for residency and become the direct factors of land conversion for development (Liu et. al., 2008). Furthermore, urban growth is more likely to be expanded if the location is closer to urban centres.

In addition, Briassoulis (2008) proposed that urban model should consider bio-physical driving forces which consist of characteristics and processes of the natural environment. Suitability of a location to develop can be impacted by bio-physical factors, for instance, slope layer needs to be taken into consideration in urban expansion model (Verburg et. al., 2004). Hu and Lo (2007) proposed that steep and elevated areas are less likely to be developed due to the cost of construction and higher risk of land instability. Factors like economic gains and insufficiency of land availability might lead developer to consider developing despite the high cost and risk of slope and elevation. Apart from that, zoning status or legally protected areas have produced the best result in sensitivity analysis of developed urban model which signify it as one of important factors of urban expansion (Poelmans \& van Rompaey, 2010).

Kuang, Chia, Lu and Dou (2014) recognised that urban planning, management strategies and policies have become major driving forces that need to be considered in modelling urban growth as they can affect other drivers. China, for example, has experienced unprecedented speed of urbanisation rate since government setting up special economic zone which has emerged as 
Mohd Amirul Mahamud, Narimah Samat \& Norzailawati Mohd Noor

Identifying Factors Influencing Urban Spatial Growth for The George Town Conurbation

China's commercial and industrial hub. On the contrary, the United States remained relatively stable urbanisation rate due to introduction to variation of distinct zone to manage rural and urban area (Kuang et. al., 2014). Instead of exercising land use policy to direct physical development, it can also serve as a platform to promote economic, social, environment and other goals which indirectly stimulate urban development (Briassoulis, 2008).

As indicated by studies undertaken in various countries, socio-economic, economy, bio-physical and political factors played an important role in stimulating urban spatial growth (Li et. al., 2013; Liu et. al., 2008; Briassoulis, 2008; Kuang et. al., 2014). Similarly, in Malaysia, rapid urbanisation was due to various driving forces that influenced urban spatial growth especially in major urban conurbations namely Kuala Lumpur, George Town, Johor Bahru and Kuantan. These conurbations have been identified in National Physical Plan 2 (NPP2) and prioritised to facilitate urban planning process (Hashim, 2011). All the above mentioned conurbations were named after the major cities that trigger rapid urbanisation to its surroundings (FDTCP, 2015b). Although urban development brought economic benefits to the country, it may also cause negative impact to the agricultural and natural areas if proper planning is not in place (Samat, Ghazali, Hasni \& Elhadary, 2014).

\section{METHODOLOGY}

\section{Data}

The primary objective of this paper is to identify and analyse possible driving forces that promote urban spatial growth, especially those that can be employed to predict future changes and their potential environmental effects. The identified driving forces were then being adapted in Malaysian context to model urban growth of George Town Conurbation. In order to achieve the objective, data from recent research journals and articles regarding modelling urban growth were reviewed. In addition, an on-line survey was conducted to gather data on driving forces of urban development. The questionnaire consists of 5 items to gather information about respondents' demographic backgrounds and another 6 items to assess their knowledge of urban development. The survey contains open-ended and closed-ended questions using Likert scale rating 1-to-9 (Saaty, 1992). Through purposive sampling, the surveys were distributed to planners from Department of Town and Country Planning (DTCP), academicians and researchers of public universities in Malaysia, private urban modellers and developers. This survey aimed to assess their perception on urban land use transformation and also to measure the weight of potential drivers or factors that stimulate urban spatial growth in Malaysia. The study managed to obtain 39 respondents with the majority of the respondents (69.2\%) aged more than 40 years old. This implies that this group of respondents have witnessed and 
experienced urban growth and development since year 1990. Apart from that, $84.6 \%$ of the respondents (33 respondents) are directly involved or are well aware of urban development. 24 respondents $(61.5 \%)$ are academicians specializing in urban studies and 9 respondents $(23.1 \%)$ are urban planners. The reliability of the online survey has been tested, especially for question related to determine the importance of a driving force in urban growth. The result, Cronbach's Alpha value of $\alpha=0.789$, indicates that the instrument is reliable. Quantitative data was analysed using Microsoft Excel 2010 and qualitative data, in the form of direct quotations, are used to supplement the findings.

\section{Identifying Weights for Drivers of Urban Growth}

In understanding the urban development phenomenon, there are factors or drivers inevitably influencing the process either explicitly or unwittingly. For example, the existence of institutions or administrative offices in an area will directly attract developers to build residential area nearby, which consequently forces local authorities to enhance public amenities and infrastructure for the community. This situation unwittingly will result in the existence of another new town which in future will expand into city. Due to the variety of factors influencing urban development, it is necessary to figure out weights or relative importance of each identified factor, which is useful for urban planners and urban modellers.

Pairwise comparison method was chosen to compute weights of drivers as this approach is a popular approach to analyse Likert Scale questionnaire (Beynon, 2002; Hossain, Adnan \& Hasin, 2014). Relative importance is computed from the ratings assigned from Likert Scale and then form a "suggestion Matrix" in order to calculate weights using Pairwise comparison method (Hossain et. al., 2014). "Suggestion matrix" in determining weights of factors are shown in the following Table 1 and Table 2 below.

Table 1 Pairwise comparison matrix considering all factors

\begin{tabular}{|c|c|c|c|c|c|c|c|c|c|c|}
\hline$\#$ & 1 & 2 & 3 & 4 & 5 & 6 & 7 & 8 & 9 & 10 \\
\hline 1 & 1 & & & & & & & & & \\
\hline 2 & 0.86 & 1 & & & & & & & & \\
\hline 3 & 1.00 & 1.17 & 1 & & & & & & & \\
\hline 4 & 0.73 & 1.00 & 0.86 & 1 & & & & & & \\
\hline 5 & 0.86 & 1.17 & 0.86 & 1.00 & 1 & & & & & \\
\hline 6 & 1.00 & 1.36 & 1.00 & 1.17 & 1.17 & 1 & & & & \\
\hline 7 & 0.73 & 1.00 & 0.73 & 0.86 & 1.00 & 0.86 & 1 & & & \\
\hline 8 & 0.86 & 1.17 & 0.86 & 1.00 & 1.17 & 0.86 & 1.00 & 1 & & \\
\hline 9 & 0.86 & 1.17 & 0.86 & 1.00 & 1.17 & 0.86 & 1.00 & 1.00 & 1 & \\
\hline 10 & 0.86 & 1.17 & 0.86 & 1.00 & 1.17 & 0.86 & 1.00 & 1.00 & 1.00 & 1 \\
\hline
\end{tabular}

$\mathbf{1 = D i s t a n c e}$ to workplace $\mathbf{2}=$ Distance to city centre $\mathbf{3}=$ Cheap housing price $\mathbf{4 = P o p u l a t i o n ~ d e n s i t y ~ o r ~}$ neighbourhood $\mathbf{5}=$ Distance to health centre eg. public hospital, public clinic, etc. $\mathbf{6}=$ Distance to public amenities eg. school, university, etc. $7=$ Distance to main road or highway $8=$ Distance to commercial or industrial area $\mathbf{9}=$ Proximity to parks and natural features $\mathbf{1 0}=$ Proximity to area that support new and growing business 
Mohd Amirul Mahamud, Narimah Samat \& Norzailawati Mohd Noor

Identifying Factors Influencing Urban Spatial Growth for The George Town Conurbation

Table 2 Pairwise comparison matrix considering some factors

\begin{tabular}{|c|c|c|c|c|c|c|c|}
\hline$\#$ & 1 & 3 & 4 & 5 & 6 & 7 & 10 \\
\hline 1 & 1 & & & & & & \\
\hline 3 & 1.00 & 1 & & & & & \\
\hline 4 & 0.86 & 0.86 & 1 & & & & \\
\hline 5 & 1.00 & 0.86 & 1.00 & 1 & & & \\
\hline 6 & 1.17 & 1.00 & 1.17 & 1.17 & 1 & & \\
\hline 7 & 0.86 & 0.73 & 0.86 & 1.00 & 0.86 & 1 & \\
\hline 10 & 1.00 & 0.86 & 1.00 & 1.17 & 0.86 & 1.00 & 1 \\
\hline
\end{tabular}

$\mathbf{1 = D i s t a n c e ~ t o ~ w o r k p l a c e ~} \mathbf{3}=$ Cheap housing price $\mathbf{4 = P o p u l a t i o n ~ d e n s i t y ~ o r ~ n e i g h b o u r h o o d ~} \mathbf{5}=$ Distance to health centre eg. public hospital, public clinic, etc. 6=Distance to public amenities eg. school, university, etc.

$\mathbf{7}=$ Distance to main road or highway $\mathbf{1 0}=$ Proximity to area that support new and growing business

\section{Study Area}

The study was carried out in the George Town Conurbation, which involves the Penang State and parts of neighbouring states of Kedah and Perak as proposed by Penang State Department of Town and Country Planning (PDTCP, 2015) and in line with NNP2 of Malaysia (Hashim, 2011). It is located in the northwest coast of Peninsular Malaysia between latitude $4^{\circ} 50^{\prime} \mathrm{N}$ and $5^{\circ} 52^{\prime} \mathrm{N}$ and longitude $100^{\circ}$ $10^{\prime} \mathrm{E}$ and $100^{\circ} 51^{\prime} \mathrm{E}$, with an area approximately 3,938 square kilometres (See Figure 1). George Town Conurbation is a metropolitan area with a total population over 2.5 million people and it is estimated to exceed 3 million residents by 2020 (Department of Statistics, 2010). As this conurbation spreads across three states, the proposed boundary of George Town Conurbation was determined by economic criteria, distance travelled and mega projects in George Town's neighbouring districts (PDTCP, 2015).

George Town Conurbation was selected as the study area because this area has experienced rapid development, especially in the industrial manufacturing, trade, commerce and services sectors (Samat et. al., 2014). In addition, its strategic location in establishing relationships and cooperation with regional countries and bordering regions are also one of the reasons for selecting this conurbation as the study area. This strategic location will intensify the northern territory's role in contributing to major economic development of the country (FDTCP, 2015b). Furthermore, George Town Conurbation is one of the four major conurbations that have been highlighted in NPP 2 which implies that the study area is very significant in the development of Malaysia (Hashim, 2011).

George Town Conurbation had also experienced a tremendous land use changes influenced by the spillover of Penang Development. Many people have been forced to sell their agricultural land as they are not able to earn maximum yield due to the development surrounding the land (Samat et. al., 2014). As a result, development has expanded based on land availability instead of following regulation made by the local authority. 
PLANNING MALAYSIA

Journal of the Malaysian Institute of Planners (2016)

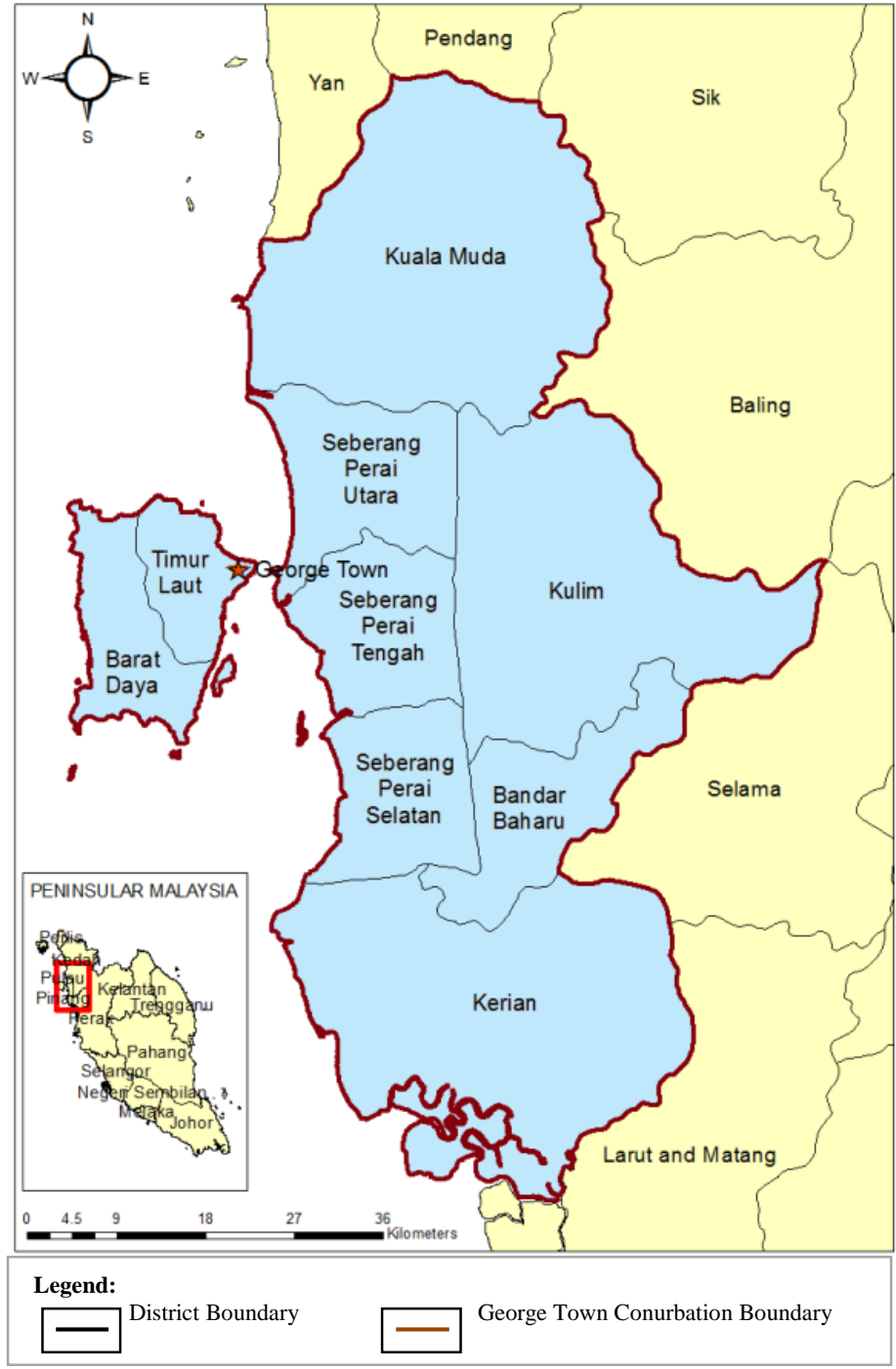

Figure 1 The Study Area (George Town Conurbation)

Source: Penang State Department of Town and Country Planning (PDTCP, 2015

Due to that reason, Landsat images of the study area have been downloaded from the United States Geological Survey (USGS, 2014) and processed using Erdas Imagine software 2014 to assess the spread of development in George Town Conurbation. 
Mohd Amirul Mahamud, Narimah Samat \& Norzailawati Mohd Noor

Identifying Factors Influencing Urban Spatial Growth for The George Town Conurbation
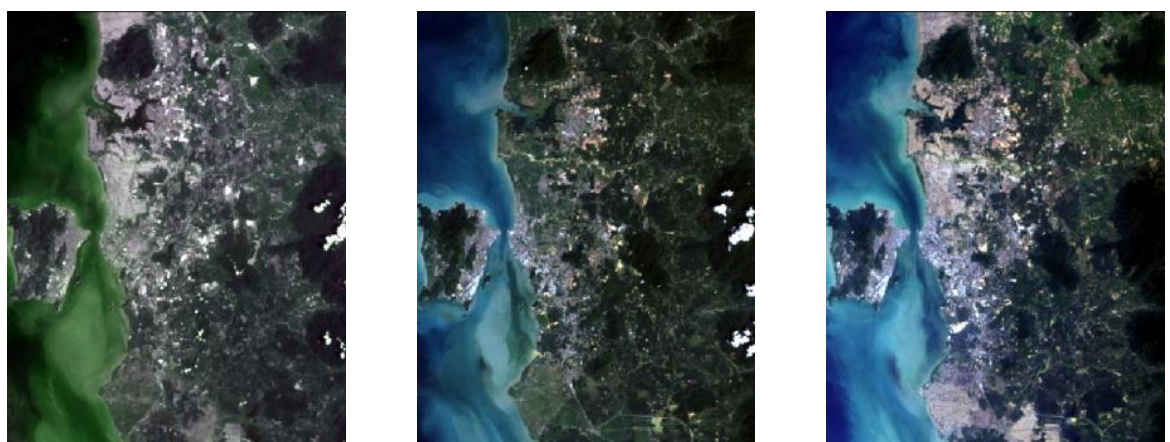

Figure 2 Landsat Image of Year 2002 (left), Year 2009 (centre) and Year 2014 (right) Source: United States Geological Survey (USGS, 2014)

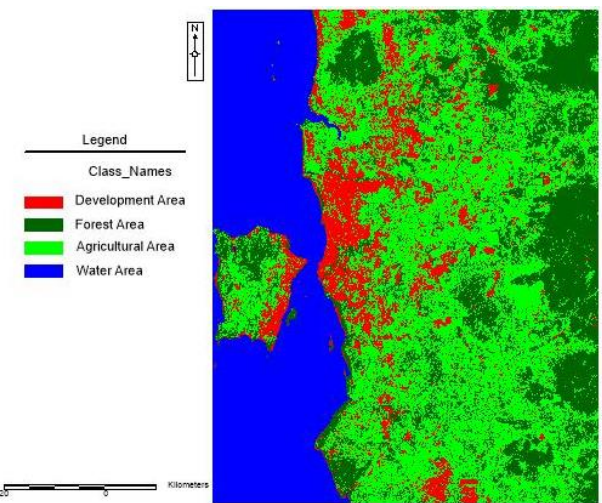

Figure 3(a) Land Cover, 2002

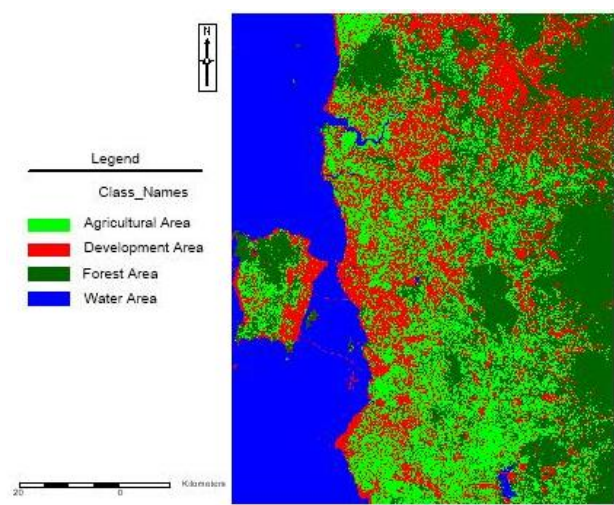

Figure 3(c): Land Cover 2014

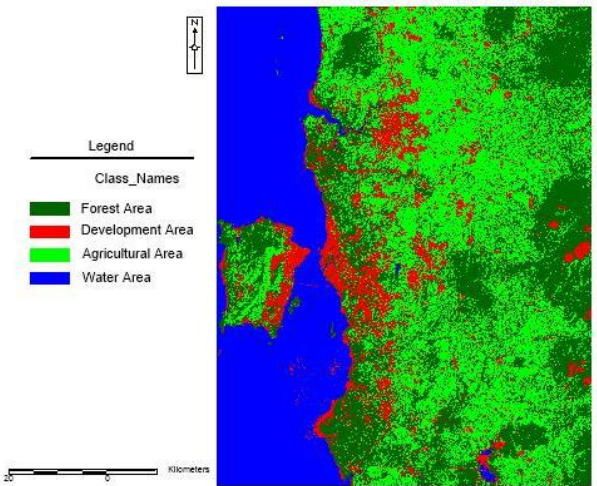

Figure 3(b) Land Cover, 2009 
PLANNING MALAYSIA

Journal of the Malaysian Institute of Planners (2016)

Table 3 Area (Hectares) Changes for Each Class Period

\begin{tabular}{ccc}
\hline Class Name & $\mathbf{2 0 0 2}$ to 2009 & 2009 to 2014 \\
\hline Water Area & 1,202 & 1,254 \\
\hline Forest Area & 32,580 & $-41,255$ \\
\hline Development Area & $8,197.3$ & $97,718.5$ \\
\hline Agricultural Area & $-41,979$ & $-57,718$ \\
\hline
\end{tabular}

Table 4 Area of Each Class for Different Year Period

\begin{tabular}{cccc}
\hline Class Name & \multicolumn{3}{c}{ Area (Hectares) } \\
\cline { 2 - 4 } & $\mathbf{2 0 0 2}$ & $\mathbf{2 0 0 9}$ & $\mathbf{2 0 1 4}$ \\
\hline Water Area & 186,999 & 188,201 & 189,455 \\
\hline Forest Area & 209,821 & 242,401 & 201,146 \\
\hline Development Area & $68,843.2$ & $77,040.5$ & 174,759 \\
\hline Agricultural Area & 284,572 & 242,593 & 184,875 \\
\hline Overall Classification Accuracy & 80.08 & 83.59 & 81.25 \\
$(\%)$ & & & 0.7474 \\
\hline Overall Kappa Statistics & 0.7366 & 0.7713 &
\end{tabular}

Based on the image classification results (Table 3 and Table 4), it can be seen that developed areas has increased from 68,843 hectares to 174,759 hectares (more than 150\% increase) from 2002 to 2014 respectively. The increase of developed areas is at the expense of agricultural land which decreased from 284,572 hectares in 2002 to 184,875 hectares in 2014 (total changes of 99,697ha). Forest area also experienced a decreasing change, from 209,821 hectares in 2002 to 201,146 hectares in 2014. These results show that George Town Conurbation has been experiencing rapid urban growth over the last decade or so.

\section{RESULTS AND DISCUSSIONS}

Based on the driving forces identified and gathered from published articles in journals, this study utilized online survey to determine weight for each factor in influencing urban spatial growth. These weights and factors will later be used in modelling the dynamic urban spatial growth of the study area. Table 5 shows the weights for each factor as indicated by the data gathered from the survey.

Table 5 Factors with Respective Weighting Value

\begin{tabular}{lcc}
\hline \multicolumn{1}{c}{ Factors } & Weight 5a & Weight 5b \\
\hline $\begin{array}{l}\text { Distance to public amenities e.g. school, } \\
\text { university, etc. }\end{array}$ & 0.1122 & 0.1589 \\
Distance to workplace & 0.1141 & 0.1457 \\
Proximity to area that support new and & 0.0977 & 0.1393
\end{tabular}
growing business 
Mohd Amirul Mahamud, Narimah Samat \& Norzailawati Mohd Noor

Identifying Factors Influencing Urban Spatial Growth for The George Town Conurbation

Distance to health centre e.g. public

0.0950

hospital, public clinic, etc.

Distance to main road or highway

0.0906

0.1276

Distance to commercial or industrial area

0.0977

$-$

Proximity to parks and natural features

0.0977

Distance to city centre

0.0879

Cheap housing price 0.1123

Population density or neighbourhood

0.0948

0.1589

Consistency Ratio

0.004

0.1362 0.001

Weight $5 \mathrm{a}$ in Table 5 are weighting values for all factors rated by the respondents, whilst Weight $5 \mathrm{~b}$ are weighting values after removing three factors with lowest mean rated by the respondents. Distance to workplace, cheap housing price and distance to public amenities have been rated by the respondents as the most important factors that affecting urban development with weights of 0.1141 , 0.1123 and 0.1122 respectively. Similarly, according to Samat (2007) proximity to employment centres have been rated as most influence factor in urban growth. In addition, the study by Samat, Hasni \& Elhadary (2011) also proved that Northern Seberang Perai in Penang has experienced an increased rate of urban growth with the development of education institutions especially in Bertam. As a result of the development of the institutions, many sites neighbouring those institutions developed rapidly while other areas grow much slower (Samat et. al., 2011).

On the other hand, the respondents have rated distance to commercial or industrial area (0.0977), proximity to parks and natural features (0.0977) and distance to city centre $(0.0879)$ as less important in stimulating urban development. Another researcher also found that proximity to population centres which is residential area have been weighted as lowest influences factors when modelling industrial activities in urban growth model (Samat et. al., 2011). This may be due to people were not comfortable to live in surroundings near to industrial area and at the same time people prefer to live in an environment free from commercial or industrial waste which can affect health of nearby communities. Another reason that may have contributed to the finding is that more efficient road network will shorten travelling time, thus distance to city centre becomes less important in promoting urban development. Samat et. al. (2011) notice that investment on transportation network such as North-South Expressway and Butterworth-Kulim Expressway in Northern Region of Peninsular Malaysia has facilitated many people to move from one district to another in a short time period. 
PLANNING MALAYSIA

Journal of the Malaysian Institute of Planners (2016)

\section{CONCLUSION}

A good dynamic urban model should be able to account identified driving forces in order to utilise land within a boundary optimally. Based on the literature review, it was found that three major driving forces stimulate urban development namely: physical landscape, socio-economic and environment. Meanwhile, respondents of the survey conducted during this study have rated distance to workplace, cheap housing price and distance to public amenities as factors with most influence on urban growth. The respondents also provided valuable data (weight) for modelling urban growth. However, some respondents also proposed that political factor should be considered in predicting urban growth. Findings from previous research proved that this political factor does have a significant impact to urban growth but it is very difficult to quantify it. Therefore, future research could investigate political factors, which influence urban growth using qualitative approach.

\section{ACKNOWLEDGEMENTS}

Authors wish to thank Ministry of Higher Education (MoHE) for funding the research through Fundamental Research Grant Scheme (FRGS) grant number 203/PHUMANITI/6711472, Federal and Penang State Department of Town and Country Planning for providing the land use data and to those who has participated in responding to the online survey in this study.

\section{REFERENCES}

Aguayo, M. I., Wiegand, T., Azócar, G. D., Wiegand, K. \& Vega, C.E. (2007). Revealing the driving forces of mid-cities urban growth patterns using spatial modeling: a case study of Los Ángeles, Chile. Ecology and Society, 12(1): 13 [online] URL: http://www.ecologyandsociety.org/vol12/iss1/art13/

Batty, M. (1971). Modelling cities as dynamic systems. Nature, 231, 425-428.

Beynon, M. (2002). DS/AHP method: a mathematical analysis, including an understanding of uncertainty. European Journal of Operational Research, 140, 148-164.

Briassoulis, H. (2008). Land-use policy and planning, theorizing, and modeling: lost in translation, found in complexity? Environmental and Planning B, 35, 16-33.

Deng, J.S., Wang, K., Hong, Y. \& Qi, J.G. (2009). Spatio-temporal dynamics and evolution of land use change and landscape pattern in response to rapid urbanization. Landscape and Urban Planning, 92, 187-198.

Department of Statistics (2010). Population distribution and basic demographic characteristics. Department of Statistics, Malaysia.

Federal Department of Town and Country Planning - FDTCP (2015a). Georgetown - Sungai Petani - Kulim Growth Management Plan, retrieved on 5 June 2015, from http://www.townplan.gov.my/download/Banner\%20Page/Georgetown_english.pdf.

Federal Department of Town and Country Planning - FDTCP (2015b) Rangka Kerja Penyelarasan Pengurusan Pertumbuhan Georgetown Conurbation, retrieved on 5 June 2015, from http://www.townplan.gov.my/download/ GTCRIN 2.PDF [In Bahasa]. 
Mohd Amirul Mahamud, Narimah Samat \& Norzailawati Mohd Noor

Identifying Factors Influencing Urban Spatial Growth for The George Town Conurbation

Hashim, N. (2011). The Planning \& Implementation of Urban Agglomeration. Kuala Lumpur: Malaysian Institute of Planners.

Hossain, M.F., Adnan, Z.H. \& Hasin, M.A.A. (2014). Improvement in weighting assignment process in Analytic Hierarchy Process by introducing suggestion matrix and Likert scale. International Journal of Supply Chain Management, 3(4), 91-95.

Hu, Z. \& Lo, C. P. (2007). Modeling urban growth in Atlanta using logistic regression. Computers, Environment and Urban Systems, 31(6), 667-688.

Kuang, W., Chia, W., Lu, D. \& Dou, Y. (2014). Comparative analysis of megacity expansions in China and the U.S. patterns, rates and driving forces. Landscape and Urban Planning, 132,121-135.

Li, X., Zhou, W. \& Ouyang, Z. (2013). Forty years of urban expansion in Beijing: What is the relative importance of physical, socioeconomic, and neighborhood factors? Applied Geography, 38, 1-10.

Liu, Y.S., Wang, L.J. \& Long, H.L. (2008). Spatio-temporal analysis of land-use conversion in the eastern coastal China during 1996-2005. Journal of Geographical Sciences, $18(3), 274-282$.

Lo, C.P. \& Yang, X. (2002). Drivers of land-use/land-cover changes and dynamic modeling for the Atlanta, Georgia Metropolitan Area. Photogrammetric Engineering \& Remote Sensing, 68(10), 1073-1082.

Lu, C., Wu, Y., Shen, Q. \& Wang, H. (2013). Driving force of urban growth and regional planning: A case study of China's Guangdong Province. Habitat International, 40, $35-41$.

Malczewski, J. (1999). Visualization in multicriteria spatial decision support systems. Geomatica, 53, 139-147.

Penang State Department of Town and Country Planning (PDTCP) (2015). Pernyataan Dasar-Dasar dan Cadangan Umum RSNPP 2020, retrieved on 5 June 2015, from http://jpbdgeoportal.penang.gov.my/jpbd/RSN/ Topik_4.0.html [In Bahasa].

Poelmans, L. \& van Rompaey, A. (2010). Complexity and performance of urban expansion models. Computers, Environment and Urban Systems, 34, 17-27.

Saaty, T. A. (1992). Decision-making for leaders (2nd Edition). Pittsburgh: RWS Publication.

Samat, N. (2007). Integrating GIS and Cellular Automata Spatial model in evaluating urban growth: prospects and challenges. Jurnal Alam Bina, 9(1), 79-93.

Samat, N., Hasni, R. \& Elhadary, Y. (2011). Modelling land use changes at the peri-urban areas using Geographic Information Systems and Cellular Automata model. Journal of Sustainable Development, 4(6), 72-84.

Samat, N., Ghazali, S., Hasni, R. \& Elhadary, Y. (2014). Urban expansion and its impact on local communities: A case study of Seberang Perai, Penang, Malaysia. Pertanika J. Soc. Sci. \& Hum., 22(2), 349-367.

Su, S., Jiang, Z., Zhang, Q. \& Zhang, Y. (2011). Transformation of agricultural landscapes under rapid urbanization: a threat to sustainability in Hang-Jia-Hu region, China. Applied Geography, 31, 439-449.

United Nations (2014). World Urbanization Prospects (CD-ROM Edition). Population Division of the Department of Economic and Social Affairs, United Nations.

U.S Geological Survey (USGS) (2014). Earth Explorer, Maps, Imagery and Publications, retrieved on 29 July 2015, from http://earthexplorer.usgs.gov/

Verburg, P.H., Schot, P.P., Dijst, M.J. \& Veldkamp, A. (2004). Land use change modelling: Current practice and research priorities. GeoJournal, 61(4), 309-324. 


\title{
This title is now indexed in Scopus

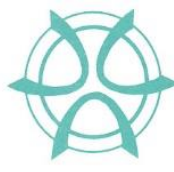 \\ PLANNING MALAYSIA: \\ Journal of the Malaysian Institute of Planners

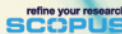 \\ VOLUME XIV (2016), Page 107 - 126 \\ THE CRITIQUES TO POSITIVISM DIRECTION OF INQUIRY IN COMPREHENDING THE COMPLEXITY OF GOVERNANCE IN MANAGING CITIES COMPETITIVENESS
}

\author{
Faizul Abdullah $^{1}$ \& Fatimah Yusof ${ }^{2}$ \\ Faculty of Architecture, Planning and Surveying \\ UNIVERSITI TEKNOLOGI MARA MALAYSIA
}

\begin{abstract}
The complexities in managing cities are real in the ethos of global cities competition and indeed, the governance of urban complexities are further compounded by the discoveries of new tangible and intangible determinants, vehemently contributed by the increased structural changes on a global scale ceased to be the main axes and reference points in societal organization. Whilst deterministic about deploying competitive cities interventions, the initiatives have always exposed local authorities to other related issues in the governance of complexity, which usually infers to their organizing capacity in attaining organizations competitiveness. For most modernists' scholars, they tend to agreed that learning is associated with efficiency and thus, it exposed organizations to learn new impositions of social artefacts. Exaggerated from realist ontology definitive foundation of structural functionalism, it clearly underlined Weberian positivism bureaucratic efficiency, which echoed local authorities in attaining the balancing act between 'de jure' and 'de facto' that constitutionally empowered in managing cities in the ethos of globalization. On the contrary, the realism in local authorities suggested otherwise, which perhaps lead to epistemological debates on the governmentality. Apparently, local authorities are facing dramatic challenges not only reframing to achieving global interventions on cities competitiveness and urban sustainability interventions de jure; but also intensely faced-off with severe ignorance, resentment and dissonance from the entire workforce itself - de facto. As such, it warrants this paper to explore the validity on the dominant used of positivism direction of inquiry among social sciences researchers' on organizational bureaucratic efficiency, when most positivism line of inquiry researchers suggested that local authorities are learning organization entities, or is it so?
\end{abstract}

Keyword: Learning organization, positivism causal law, heretic behaviours 
Faizul Abdullah \& Fatimah Yusof

The Critiques to Positivism Direction of Inquiry in Comprehending the Complexity of Governance in Managing Cities Competitiveness

\section{INTRODUCTION}

The subject to this insight dwelled with the credence of local authorities in managing cities in the ethos of global cities competition. For analytical purposes, it is not the intend to negates on how local authorities deploying competitive urban policy, but most importantly is to evaluate the merits of local authorities to response to the dynamic notion of management innovation, which lead to questions their organizing capacity in translating those competitive cities management policies into practices. The term management innovation, coined from Mehta (1998), refers as the dynamic concept of urban governance of local authority in their efficacious efforts in translating competitive cities management. In due process, it implies to the capabilities of decision makers in local authorities to shape and sanction management innovation and the executive management to manage, and the urban managers to implement it. Compelled to view the issues entailed from interpretative perspectives that encumbered organizing capacity of local authorities, it subsequently leads this insight to evaluate the underlined phenomena of endemic behaviours that impeding learning values in organization, which posit the notion of learning organization.

As evolutionary as the paradigm of competitive cities management todate, so does the management of local authorities, exposing them to the only constant attribute, the dramatic changed environment. Evidently, the neoliberalism approaches are behind this long-winded movement of the global cities competitiveness. Reckoned on the intensity, the UN Millennium Declaration was conceived in 2000, supported the idea of cities sustainability whilst encouraged local authorities to re-invent in its strategic response. At this point, issues relating to governance of urban complexities are central, consistently highlighted by most urban management scholars in obviating cities marginalization and social exclusion. Nevertheless, literatures in relation to city governance are abound, but seminal works from Azmizam, et al (2009), and Hamzah and Azmizam (2008) are much related to local flavours since they did emphasize on the complexities, and presenting Kuala Lumpur city-regions in detailing the challenges endured in the governance of urban complexities in the ethos of global intensities. Despite to the similarity in line of inquiry between them, they reckoned the importance of global cities circuits, which ontologically, merits local authorities to manage these issues in tandem with the global concerned and to response amicably to accommodate the governance complexities.

Imbued by the idea of organizational efficiency, local authorities are further circumspect to re-visit their own organizing capacity, which is yet another plausible rule that needed attentive effort. In view of its importance in balancing between de jure and de facto, the management innovation and public sector capacity for good governance initiatives was later endorsed during the summit of Mexico 2003 Global Forum on Reinventing Government Capacity. Seemingly, 
PLANNING MALAYSIA

Journal of the Malaysian Institute of Planners (2016)

all these intervention necessitates the efficacious attempt by local authorities to re-consolidate their organizing capacity, where all aspects of cities innovation systems are a priori to cities competitiveness and sustainability blueprint. In due processes, it warrants local authorities to un-learned their present approaches and be transformative structurally, in coveting competitive cities management - the lessons endorsed throughout the global interventions. However, prior to comprehend the importance on the framework of cities innovation systems, it is important to theorize local authorities as learning entities, as the term entailed a compelling meanings representing a powerful institution in sanctioning competitive cities management.

\section{THEORIZING LOCAL AUTHORITIES AS LEARNING ORGANIZATION ENTITIES}

Let us begin by quoting to some of significant captions from Zuboff's (1988) in her works "In the Age of the Smart Machine", where she equated learning capacity as values in attaining organizations competitiveness. In her attempts, she highlighted that in "today's organization may indeed have little choice but to become a 'learning institution', since one of its principal purposes will have to be the expansion of knowledge - not knowledge for its own sake, but knowledge that comes to reside at the core of what it means to be productive. Learning is no longer a separate activity that occurs either before one enters the workplace or in remote classroom settings. Nor is it an activity reserved for a managerial group. The behaviours that define learning and the behaviours that define being productive are one, and the same. Learning is the heart of productive activity. To put it simply, learning is the new form of labour". Obviously, that idealism signified her concerned, hedging learning values to some deliverable [economic] inputs, as organization assets. Indeed, she did lay a definitive foundational that situates learning as every workforce affair, responsibilities to attained and uphold with honour. The tenet to her idealism is when she put the thrust, believing that every workforce is able to solve problem amicably by his or her own innate culture for efficiencies, a culture that becomes the repository for lessons learned, which situates workforce as asset in organization.

However, the realism turned out to be different, leading to pertinent questions involving the 'capacity in need' required in translating good governance that supposedly build by everyone. Indeed, the reality is when local authorities are facing with dramatic challenges from both ends, not only accountable to achieving global benchmark in competitive cities management interventions but also, concomitantly facing an intense apprehension from the entire workforce itself, from within. As represented in Figure 1, it exhibited the dynamism of organizing capacity of local authorities, depicting their purposive attempts to response to the global competitive fundamentals in managing cities competitively. This representation holds to addressed complexities of governance 
Faizul Abdullah \& Fatimah Yusof

The Critiques to Positivism Direction of Inquiry in Comprehending the Complexity of Governance in Managing Cities Competitiveness

by way of continuous knowledge acquisition, for one competencies and skills enhancement through lots of training investments. The intention is simple when the acquired knowledge would reciprocate with competencies and skills. Such induced and control behaviours would allow to the construction of systemic selfauditing artefacts in organization. Resembling the Weberian approaches of bureaucratic induction for efficiency would often leads to efficient forms of social control that enabled individuals to govern and behave.

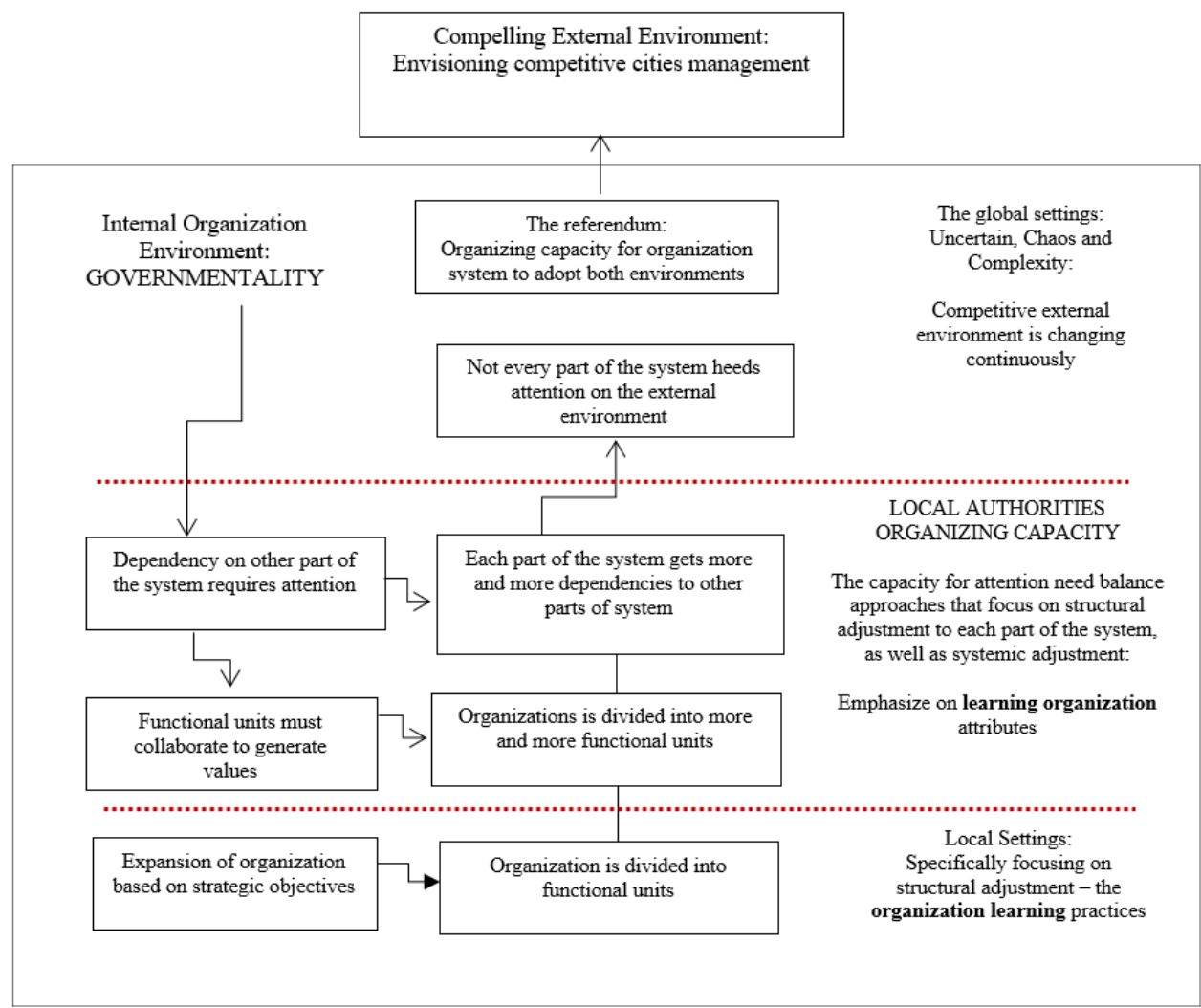

Figure 1 Organization dynamics and the probabilistic causation relationships Source: Faizul A. 2015

Against the globalization intensities and uncertainties, it could certainly have promised one thing; the interactions and integration of global cultures, politics, businesses and intellectual elements have profoundly infiltrated and transformed the cultural cognitive and intuitive for most organizations and local authorities are not sparred either. Now, the interesting part is viewing the standardized 'bureaucracy for efficiency' approaches favourably adopted in most organizational transformation plan. Sometimes, it is 'too old fashion' when 
PLANNING MALAYSIA

Journal of the Malaysian Institute of Planners (2016)

inducement of social artefacts usually resembled a regimented, top-down, single ways of communication flows, but often seen as norms in organizational development, and robustly supported with streams of trainings methodologies, on the premised in enhancing individual competencies and skills. However, the sustainable of training methods and the acquisitions of knowledge is questionable, when the dissemination and utilization of acquired knowledge is yet to be tested. Seemingly, the approach to good governance is open for further contestation when the issue now lies on how each individual in organization behaves and act systemically to their purposive actions, where their praxis of governmentality is now inferring in redressing the complexity of governance.

For the term governmentality, it is devised from Foucault (1991), when he refers to the "art of government" or governing, that includes the used of development approaches that is consistent with appropriate theory, policy and practices by local authorities that have had the consequential effects on urban governance. Nonetheless, it should not be construed to the meanings with the simple act of governing in a strict sense, because it may also include the way the mayor or the president, executive directors and urban managers governs or conduct and behaves themselves. However, by giving much attention to served urban communities and stakeholders, their credence is sometimes being challenged from their own backyard. This is when the issue of governmentality arise that could be destabilized the practices [de facto]. These are the realities, when their own workforce impeding their organizing capacity internally, with apparent ignorance, resentment and dissonance assimilated by myopic prejudgment and dogmatic perceptions among workforce. The repercussion is obvious when most organizations [including local authorities] are experiencing hard failed transformation plan due to these endemic values. Perceived as the irredeemable behaviours and indeed, it could turn out as liability to local authorities when un-productive and un-operative individual self-have had dominated organizations culture ${ }_{2}$ which clearly demonstrated that institutional interdependency among leaders [decision makers and urban managers] and the entire workforce are fragile.

For the term institutional interdependency, it is a composite terminology derived, based on reviews from the scholarly works. It refers to dynamic notion of cohered relationships of being mutually consented between individual that is ascribed to 'unity of essential will' ethos. While collaborating through untraded dependency (Storper, 1998) to any responsibilities assigned, they shared basic assumptions pattern (Schein, 1993) and systemic envisioning (Senge, 1990) to execute common values based on ethical and moral principles (Bandura, 1997) with others individual or unit in public agencies. In the absent of cohered institutional interdependency, the 'unity of essential will' is far-fetched. The acculturations of learning values are unconceivable where the entire workforce is unable to envision organizational strategic objectives through shared vision. But 
Faizul Abdullah \& Fatimah Yusof

The Critiques to Positivism Direction of Inquiry in Comprehending the Complexity of Governance in Managing Cities Competitiveness

the realities would not work in tandem to the defined meanings, as most performance-based management instrument turned out to be a 'punishment' artefact for workforce and not well accepted by the majority. It is now important to determine the causal to the ignorance, resentment and dissonance behaviours that reciprocate to weakened institutional interdependency. In response, it is analogous to the question on ' $h o w$ ' the mayor or the president, executive directors and urban managers behave in their attempts to practice good governance.

As such, it warrants this paper to theorize their cognitive choices based on free volition, inspired by the 'need to response and act consistently to their purposive actions', which subsequently leads to explain the existence of dialectical relationship in organizations. The equation is clear, where cogent organizing capacity is significantly dependent on cohered institutional interdependency. Underlined this direct causal, it posits further into another epistemological debates, when the dialectical relationships among workforce is theorize as the main attributes in destabilized the pattern of governmentality. Subsequently, de-stabilized pattern of governmentality would characterize local authorities as not the learning entities. It depicted that dialectical relationships are the reflection of antagonistic strains existed in organizations, which normally, the resultant effects are into their behaviours. Severe apprehension from workforce in any changed program initiatives aligned to organizational transformations is obvious. Even though, the epistemological interpretation varies, the circumstantial evidences often led to social marginalization and exclusion to the entire workforce in local authorities. It surely raises concerned among scholars and practitioners, when most progression to strategic roles and responsibilities during organizational transformation are not well received, instead held back by these endemics.

These are testament in local authorities, when heretic behaviours have had infiltrated profoundly as intervening cultures that affects the credence of local authorities' organizing capacity. Rephrasing Cohen (1987) definition, the heretic refers 'when workforce see themselves whose beliefs do not wholly conform as productive and learning staffs, and yet they think themselves as prominent and privilege appointed staffs'. In due process of organizational transformations, the divisional of thought within the whole organizational structures disintegrated, undo relational fragility and these values could increase the likelihood of resistance, the prevalent situation of incongruity of thought in local authorities. The tensions of incongruity encourage workforce to continuously negate and resent to any program initiatives, which situates difficulties in attaining organizational vision and mission. The heretical behaviours would in turn reciprocate to their praxis of knowledge, on being inoperative and unproductive workforce, and therefore, considered as liabilities to local authorities' performances. It is destructive values exhibited and in a long run would instigate to complexities of governance. 
Clearly, the complexities of cities governance should not solely dependent on how well competitive cities policies are being adopted, but also to give emphasize to the aspiring 'willingness of the involved workforce' during the progression of organizational transformation. It would be very unfortunate for local authorities to side-line the power of the mass that make up from their own workforce. Indeed, most management scholars have deliberated and agreed that workforce is regarded as the asset to organizations including local government. Therefore, it is appropriate to seek justification on the importance of these salient imperatives - the learning workforce, in enhancing organization capacity for nonprofit organizations by the acculturation of learning aptitude in local authorities. Relatively, this representation is consistent with Baker (2002) when he reemphasized on the development of learning organization, and viewing organization capacity is much dependent on the development of every individual's efficacious attempt within the organization and acknowledged that learning as competitive values.

\section{THE CRITIQUES TO THE SCHOLARSHIPS OF LEARNING ORGANIZATION}

In the early 1980s, the concept of learning organization [LO] conceived and regarded as powerful management tools, developed for organizational efficiency and competitiveness especially in the epoch of globalization. Anew contemporary organizational development paradigm, it emphasizes on the 'reintegration' or inclusiveness of workforce into organizations. It is an un-conventional attempt against traditional organizational management, when soft-tacit knowledge workforce is reckoned as organizations' assets. Nonetheless, this proposition is supported with theoretical strands, as envisaged by major proponents, as well as the founders of LO. Among them, the major proponents and advocators includes Schon (1983), Senge (1990), Pedler, et al, (1991), Garvin (1993), Argyris (1995), DiBella, et al (1998), Marsick, et al (1999) and Marquardt (2010) and they are highly refereed modernist-contemporary organizational management gurus. From the founder and proponent of LO him-self, Senge (1990) defined learning organization as one that is continually expanding its capacity to create its future. It is a commendable proposition, when he equated organization values to competitive advantage, which derived from continuous learning from workforce and in due processes, interdependent relationship developed and leads to the highly referent learning flagships. From here, the definition leads to the fundamental in theorizing that learning organization as competitive values in enhancing organizing capacity. Its values are embraced when workforce tend to put aside their old ways of thinking (mental model), continuously learns to be open with others (personal mastery). 
Understand how organization works (system thinking) is a priori and form a plan that everyone can agree on (shared vision) and subsequently, exerting efficacious efforts in tandem with others (team learning). Since then, streams of learning organization theories evolved, and most are giving emphasized on the interdependent relationship between individual and organizational learning, and viewing individual as the agent of organizational learning and change. As represented in Table 1, it displayed some of the contemporary literatures on the notion of a learning organization. Upon extensive reviews from previous empirical researches on learning organization, mostly are predisposed to the precept of organizational learning theoretical strands, and this is when the negations start, when this paper discovers the gap that lead to chaotic in research clarity on learning organization. This, as both terms 'organizational learning' and 'learning organization' are interchangeably used, and for that, often caused ambiguity in the attempted researches, as envisaged by DiBella, et al (1996). Since then, the emergent of various terms are obvious, deliberately defined and described in almost countless different ways, and to the extent it caused confusion to the thematic clarity, definitions and usually enticed to further criticism and negations upon fundamental theories.

Table 1 Learning organization and culture of building organizing capacity

\begin{tabular}{clc}
\hline \multicolumn{1}{c}{ Theorizing Learning in Organization } & Author/year \\
\hline $\mathbf{1}$ & $\begin{array}{l}\text { A bureaucracy embarks on a course of reflective practice, allowing } \\
\text { workforce to experience confusion and uncertainty, subjecting his }\end{array}$ & Schon, 1983 \\
frames and theories to conscious criticism and change, and may lead \\
to increasing his capacity to contribute to significant organizational \\
learning.
\end{tabular}


PLANNING MALAYSIA

Journal of the Malaysian Institute of Planners (2016)

6 Organizations can be thought of as learning systems, when values, norms, procedures and business performance data are communicated broadly and assimilated by members, starting with

DiBella, et al., 1995 early socialization and continuing through all types of group communications, both formal and informal.

7 Learning organization as one that is characterized by continuous learning for continuous improvement, and by the capacity to transform itself.

8 A learning organization is seen as a form of organization that enables the learning of its members in such a way that it creates positively valued outcomes, such as innovation, efficiency, better alignment with the environment and competitive advantage.

9 To obtain and sustain competitive advantage in this new environment, organizations will have to learn better and faster from both success and failures. They will need to continuously transform themselves into learning organization, to become places in which groups and individuals at all levels continuously engage in new learning processes.

Source: Faizul A. 2015

Consistently, Elkjaer (1999) works seek to re-affirmed the causal to the ambiguity, in which she expertly noted that most previous researchers are seemingly "drifts away with new definitions and approaches that break up rather than construct a theory" in their interpretations, which lead to various bearing of organization entities into being a learning organization. It is very unfortunate, despite knowingly the divergence in the directions of theorizing, the interests from researchers in viewing social reality from the perspectives of learning organization are vigorous. To surmise, most extended empirical researches are premised into two separate directions of theorizing and yet, used similar and related strands of literatures - the organization learning and as such, this insight can conclude that the previous researchers' interests are classified and categorically summarizes as follows:

i. Mostly are based on organizational setting, and using the behaviourism approach that is hedged to structural functionalism line of inquiry and as such, do not reflect the realism of the subliminal attributes from the mass - the cognitive relational and other unknown variables that influenced social artefacts.

ii. Most are focusing on firms' and private organizational competitiveness, instead of giving emphasized on the non-profit organizations and public agencies. 
Faizul Abdullah \& Fatimah Yusof

The Critiques to Positivism Direction of Inquiry in Comprehending the Complexity of Governance in Managing Cities Competitiveness

iii. Focusing on learning organizations but the foundational to the research thematic clarity is often drawn upon ideas from organizational learning theoretical streams.

iv. Predisposed to strict structural functionalism approaches, instead of symbolic-interpretivism approaches in the line of inquiry.

v. Giving emphasizes to evaluate organizations on social settings instead of cognitive settings.

It is pre-requisite to acculturate learning values in organization where every workforce is encouraging to continuously 'learn to unlearn' the present thinking of doing things. The purpose is to obviate dogmatic and myopic thinking that succumbed to pre-judgment. Therefore, encouragement to symptomatically envisioning organization competitiveness is crucial, and this proposition is consistent with scholarly finding from Marquardt (2010), when he suggested that enabling learning values are seemingly the most appropriate tools for organizations to hedge competitiveness. Back to the thematic gaps, it is important in the next explanatory to construct the learning continuum and subsequently lead to explain to the gapping, the divergent in the research clarity using a similar theoretical line of inquiry.

\section{THE CONSTRUCT OF LEARNING ORGANIZATION ORGANIZATION LEARNING CONTINUUM}

It is crucial now to focus the thematic clarity by deciphering the organizational learning [OL] and learning organization [LO] continuum. To simplify the congruent notion and differentiate the continuum, this paper would aptly expand the work from Festinger, et al (1950) and Elkjaer (1999). For the former, they envisaged that the construct of these "forces" and "bonds" among individual are categorically differs between ideation relationships and relational relationships and yet for both, it holds the group together among members of the group, and that would be analogous to the defining meanings. Further reviews on the causal differentiation to the underlined gestalt, it revealed that an ideational archetype refers specifically to the psychological perceived needs relationships, or this paper termed it as the cognitive relationships among members within a group. Secondly, it refers to the relational archetype that correspond to the emergent property that exhibit some form of induced-based archetype, which also denotes to some linkages among members. Nonetheless, it is still premature to precisely categorize the themes since both archetypes are profoundly focus on the structural relationships in organizations that signify the capability to construct social solidarity and commitment. However, upon further reviews from Elkjaer's (ibid) work, the differences are indeed make more sense to avoid ambiguous as she laid 
PLANNING MALAYSIA

Journal of the Malaysian Institute of Planners (2016)

the fundamental in deciphering the organization learning and learning organization continuum.

In her expertly reviewed, she positioned her reviews based on the positivism perspectives, which conclusively revealed that OL deals with the meanings on how learning occurs but an induced environment with impounding social facts. Reckoned that learning is inevitable part of participating in social life and practices, the explanatory suggested that learning did take place whenever social facts and structural settings to organizations environment, and therefore, organization learning signifies the processes engaged duly in any organizational change. However, too focusing on social facts and structural settings would induced to the building of relational network, inclined to 'unity of arbitrary will' relationships, which in a long run could spike the formations of groupthink. It is just like attending a training sessions or workshops, on a premised in enhancing competencies and skilled, but on the other score, it is often associated with triad or dyad formation, comforting within their own tolerance values. Indeed, it could be true but in the epoch of competition, training should go beyond learning. As agreed by Marquardt (2010), when learning should be emphasizing, instead much focuses on trainings. While reckoned the importance of training for competencies, it however, signifies a one-way transfer of established wisdom or skill from the expert instructor, whereas learning varies in its approach while giving emphasize on bottom-up approaches. Technically, learning involves not only absorbing existing information but also creating new solutions to problems that is not fully understood by the majority. Learning may take place with or without instructors [teachers] because it is a personnel, group and organizational ability. As represented in Table 2, it depicted some of the significant contrast in defining the meanings between training and learning.

Table 2 Contrast between training and learning

\begin{tabular}{ll}
\hline \multicolumn{1}{c}{ Training } & \multicolumn{1}{c}{ Learning } \\
\hline $\begin{array}{l}\text { From the outside in, done by } \\
\text { other }\end{array}$ & From the inside out, learner motivated \\
\hline Assumes relative stability & Assumes continuous change \\
\hline $\begin{array}{l}\text { Focuses on knowledge, skills, } \\
\text { ability and job performance }\end{array}$ & $\begin{array}{l}\text { Focus on values, attitudes, innovation and } \\
\text { outcomes }\end{array}$ \\
\hline $\begin{array}{l}\text { Appropriate for developing } \\
\text { basic competencies }\end{array}$ & $\begin{array}{l}\text { Helps organization and individuals learn how to } \\
\text { learn and create novel solutions }\end{array}$ \\
\hline Emphasizes improvement & Emphasizes breakthrough (metanoia) \\
\hline $\begin{array}{l}\text { Not necessarily linked to } \\
\text { organization's mission and } \\
\text { strategies }\end{array}$ & $\begin{array}{l}\text { Directly aligned with organization's mission and } \\
\text { requirements for success }\end{array}$ \\
\hline $\begin{array}{l}\text { Structured learning experiences } \\
\text { with short-term focus }\end{array}$ & $\begin{array}{l}\text { Formal and informal, long-term future oriented, } \\
\text { learner initiated }\end{array}$ \\
\hline $\begin{array}{l}\text { Source: Marquardt, 2010 } \\
\end{array}$
\end{tabular}


Faizul Abdullah \& Fatimah Yusof

The Critiques to Positivism Direction of Inquiry in Comprehending the Complexity of Governance in Managing Cities Competitiveness

When too much focusing on training, it would subjugate the acculturation of learning values when apparently, trained, skilled and competent individual does not guaranteed collectivism bearing to "the purpose of existence" among workforce, and subsequently it does not guarantee learning organization. Underlined these representations, it demonstrates the second line of inquiry is of valuable to comprehend, adopted from Elkjaer's work in setting the framework to establish the taxonomy, when she envisaged that LO is reckoned as tools for developing tacit, establish cognitive relationships and thinking abilities of individual members in organizations. Underlined this representation, she clearly equates LO as management tools used continuously in enhancing management innovation and most importantly is when she did emphasize on the 'cognitive relationships', which personal mastery. It is consistent with Festinger, et al (ibid) on the ideation relationships seems capable in enhancing group or team mastery build over shared vision and eventually attaining institutional interdependency among workforce. Nonetheless, these relationships resonated Durkheim's precept to the 'unity of essential will' and concomitantly resembled Senge's systemic thinking towards envisioning the common purpose of existence among workforce and their relationships are based on the 'willingness' subject to Bandura's principal of morality and ethic.

Therefore, the above representation would have laid the foundation in the construct of the continuum, where basically, organizational learning signifies the processes that represent the organizational realism by emphasizing the development of performances measurement and training and techniques and that the expected outcomes are hedged to a desirable efficiency. On the other hand, learning organization represents the organizational idealism by envisioning of 'what should it be, the convictions to uphold and the purpose of existence' which is a philosophical thought indoctrinated. By combining both approaches, the composite to the construct between OL and LO continuum is established, as represented in Figure 2. 


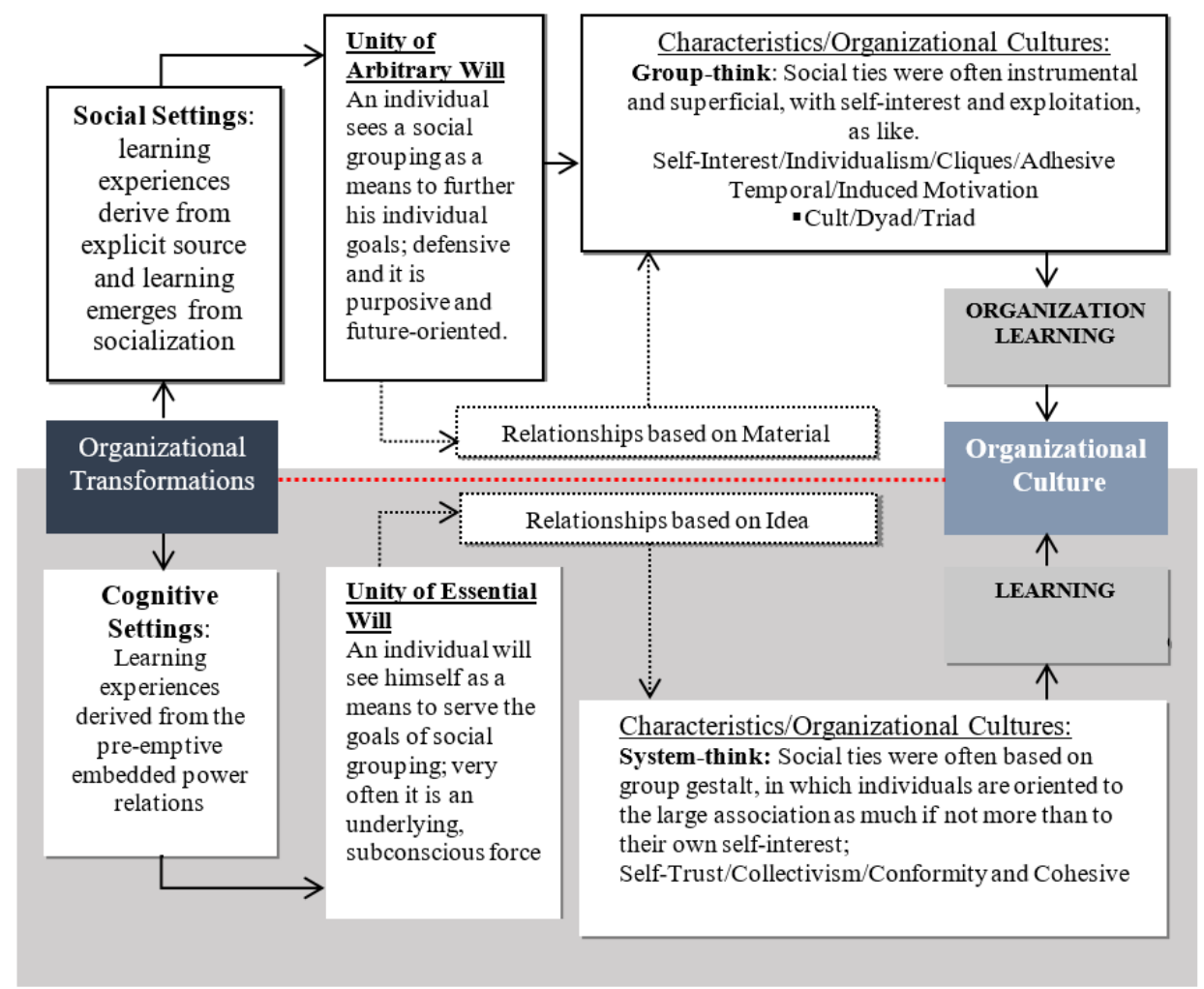

Figure 2 The continuum between organization learning and learning organization Source: Faizul A. 2015

\section{THE DEDUCTIVE LOGIC TO INTERPRETIVISM DIRECTION OF INQUIRY}

For most positivists, they viewed dialectic relationships as the reciprocating processes of self-realization of individual beings as responses to new formation of social artefacts deployed in organizations. Indeed, positivism is widely used references to obtained scientific explanation to the direct causal relationships that influence human behaviours. This representation is consistent with the dialectic relationships reviewed extensively by Maesen, et al (2005) in his interpretive works based on Jurgen Habermans's Theory of Communicative Action (1989). However, their critiques are winched to the realist ontology continuum when assumptions are laid in justifying the bearing to the relationships. If there is any feature representing dialectical relationships, it is normative in most organization. Even if it does give repercussions to organizational efficiency, the normality is to have another anew impositions of social facts that are assumed capable to stabilized chaos. For that, it clearly underlined positivism sturdy principles and the direct causal explanation to any social reality is usually hedged the 
Faizul Abdullah \& Fatimah Yusof

The Critiques to Positivism Direction of Inquiry in Comprehending the Complexity of Governance in Managing Cities Competitiveness

foundational framework to the 'what' factors to have caused the dialectical relationships.

As such, for most erudite positivist researches, they are inclined to descriptive research design. In the context of this paper, assumptions are laid in justifying that the severity of globalization have to some degree gives impact to the de jure of local authorities and therefore, situate them to some adjustments, strategic and structural reforms in reshaping the practices [de facto]. Hence, adopting the competitive cities policies and procedures are seemingly appropriate and prevalent, which again gives credence to positivism line of inquiry when they established the 'what' direct causal on the impacts onto organizations. They ardently hold the intensities of the global competition as only additives and for that, organizations could have bolstered it to any competitive urban policies and localized it in suiting their organizing capacity. As the results, appropriate social facts are established and new performance-based management procedures are always induced, in maintaining rules and order. For positivists, they are too deterministic in constructing the direct causal explanation and assuming that the new social artefacts would stabilizes chaos.

On the contrary, this paper viewed the realities otherwise and questioning the sustainability of the instruments used in future. The premise to this argument is by comprehending De Vaus (2001) literatures, and his concerned in the nature of matured organization that "is odd and hard to conceived" to any anew artefacts, which leads to the existence of social marginalization and exclusion in organizations. The resultant to these behaviours of "odd and hard to conceive" will invariably resulted in not so meaningful outcome to any change initiatives of organizational transformation in local authorities. Nonetheless, complexities in governance are beyond organizational change, where the endemics behaviours have imbued organizational cultures and values. To note, this innate cultures are powerful packed cognitive evolution that leads to the endemic behaviours. From the nominalist ontology standpoint, it will never be possible to justify the 'what' factors to explain any direct causal positivistic statements. Clearly, this argument debunked positivist limitations, when they give less emphasized in explaining the 'why' factors to the issues in explaining the credence of institutional interdependency in local authorities. Thus, it leads this paper to explore the fundamental to the 'why', even though trainings over huge investments are allocated and implemented that supposedly enhancing organizational organizing capacity through the development of human capital in local authorities. Over time, it seems certain to predict that the heretical behaviours could intensify chaos and complexity in local authorities and the credence of organizational capacity are fast fading.

These circumstances could impute to the phenomenal disintegrations among units in local authorities, which justified De Vaus (ibid) concerned on 
PLANNING MALAYSIA

Journal of the Malaysian Institute of Planners (2016)

social marginalization and social exclusion in organizations itself. From the above elaboration, due to its rigidity, this paper could conclusively view that positivistic line of inquiry has delimit in its perspectives in explaining the 'why' factors that underlined the existence of unknown subliminal which causes untoward social reality in organizations. In summary, they [positivists] mostly undermined other subliminal subjectivities and always downplays individual's subjectivity or internal reasons or any sense of free choice or volition, and is less central that exert regimented choices over needs and aspirations. Fundamentally, this drawback has prompted this paper to holds on to another mode of inquiry and this is when interpretivism approach comes to the fore. As it is explanatory research design, the used of interpretivism approach is apparent as it attempts in explaining on the ' $w$ hy' factors to determine the causal relationships that impute to organizational heretical behaviours that encumbered the credence of institutional interdependency. Usually, interpretivist always regarded individual as having dominant volition and being able to make conscious choices and most chosen choices are induction-free from social artefacts. In other words, subjectivities that one has cherished could profoundly influence them and other individual in making the choices.

\section{THE DEFINITIVE CAUSAL EXPLANATION TO THE DIALECTIC RELATIONSHIPS}

As the line of inquiry is established, this paper would further support the provisional assumptions in explaining the in-direct causal on the strenuous relationships among workforce. As regarded earlier, the underlined fragility in the institutional interdependency have profoundly ingrained as organizational cultures and values. As such, the provisional assumption that this paper anticipates is that the successes or failures of organizational management innovation are significantly dependent on the institutional interdependency among the social unit in organizations. Meanwhile, the values of learning in organization is determined as the intervening variables and it is based on the precept of learning organization, and NOT hedged on the principles of organizational learning as most previously studies have empirically concluded. In support, scholarly research conducted by Ingraham, et al (1999) and Kaplan (2003) are much anticipated. Upon comprehending both reviews, this paper could have surmised that hard failed organization change initiatives are mostly due to the element of subjectivities that it is less explored. Therefore, the provisional assumption to heretical behaviours encountered in most public agencies' against organizational transformations initiatives should therefore be hedged to the salient enabler in acculturation of learning values in organization - the organizational systemic thinking.

However, system thinking could be spurious when it is regarded as the antecedent test variable to both institutional interdependency and management 
Faizul Abdullah \& Fatimah Yusof

The Critiques to Positivism Direction of Inquiry in Comprehending the Complexity of Governance in Managing Cities Competitiveness

innovation. Indeed, Nueman (2011) concerned on spurious relationships deemed justified when two variables in any association can be fallible, where these variables are associated but not casually related, due to other unknown and unseen third factor. Earlier, Babbie (2009) have also asserted his concerned that the test variable is antecedent in nature to the causal relationships where it can both be independent and dependent variables. In the attempt to obviate antecedent variable, this paper anticipates, there are links of unknown intervening variables forming a more complex causal relationship whereby the unknown or unseen variables may probably more apparent that underlined the real cause to the fragility in institutional interdependency. As such, a deductive logic to determine the third unknown variable is to theorizing one psychological behaviour against the expectancies outcomes by emphasizing from the streams of interpretivism perspectives. As such, it holds to the precept of self-efficacy that is principally hedged to the pattern of governmentality, where the praxis of governmentality is based on precept of free volition, which is consistent with Bandura (1994) reiteration as stated, "A strong sense of efficacy enhances human accomplishment and personal well-being in many ways. People with high assurance in their capabilities approach difficult tasks as challenges to be mastered rather than as threats to be avoided. Such an efficacious outlook fosters intrinsic interest and deep engrossment in activities. They set themselves challenging goals and maintain strong commitment to them. They heighten and sustain their efforts in the face of failure. They quickly recover their sense of efficacy after failures or setbacks. They attribute failure to insufficient effort or deficient knowledge and skills that are acquirable. They approach threatening situations with assurance that they can exercise control over them. Such an efficacious outlook produces personal accomplishments, reduces stress and lowers vulnerability to depression".

Conclusively, it is important to consider self-efficacy as the subliminal attributes that exhibited the ability to invigorate and unifying four other values within the precept of learning organization, as envisaged earlier by Senge (1990) that includes the personal mastery, mental model, team learning and shared vision. This mediator or intervening variable suggests the importance of governmentality and its significant relationships would cause the mayor/president, executive directors and urban managers demonstrate consistencies to the pattern of institutional interdependency. Hence, the definitive causal relationships would explain how the pattern of governmentality is dependent on internal psychological event of self-efficacy. This cogent ideation relational demonstrates that individual self-efficacy towards cities management is consistent throughout the organization and eventually leads to consistent pattern of in governmentality, and in return established a cohered institutional interdependency in local authorities. The definitive causal law would now able to measures the psychological aspects of individual self-efficacy embedded by the 
councillors, executive director and urban managers in governing to the ascribed roles, based on the precept of self-efficacy. Therefore, as represented in Figure 3, the termed self-efficacy would now refer to the cognitive and beliefs consistencies throughout workforce in translating into one's actions as ascribed roles and that is what they do, to shape, manage and implement urban competitive policies.

In summary, the definitive causal relationship is established whereby the spurious intervening of systemic thinking is obviated and replaced by now the known subliminal intervening variable - self-efficacy. Subsequently, the construct to the measures will determine the patterns of governmentality among workforce engender - the heretic behaviours that thus, the pattern of institutional interdependency is established. The tenet to the measurements is to seek explanation on the cognitive consistencies among the management tiers that represent a cohered governmentality. Further, on, the measures would also establish and explain the existence of heretical behaviours, embedded by ignorance, resentment and dissonance in their thought that situates to the pattern of institutional interdependency. However, the questions remain on what are the variables involved that would subjugate organizational pattern of governmentality, that complete the task in determining the definitive causal relationships.

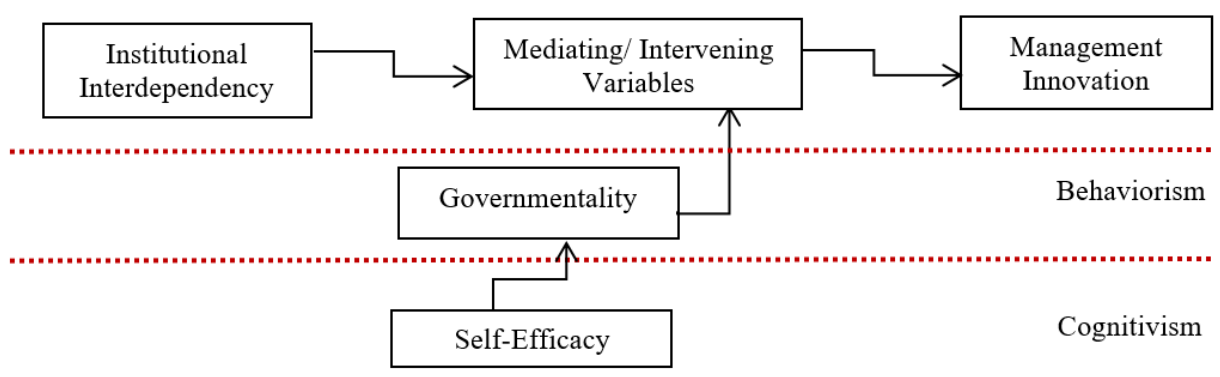

Figure 3 The definitive causal law to the in-direct probabilistic causal relationships Source: Faizul A. 2015

\section{CONCLUSION}

To end, this paper could conclude that being a learning organization and the acculturation of its values are arduous task ever tolerated by most public agencies, including local authorities. To this regards, and if left unchecked it may further expose local authorities into being an unlearned entity, vulnerable in its organizing capacity in the construct of cities innovation systems. The concrete evidences to the formation of heretics as organizational cultures would further instigate the formation of triad or dyad, the sacred groupthink. It happened when individual transmits and receives symbolic communication [cognitive] through their socially interaction, and the worse is when the transpired communications 
Faizul Abdullah \& Fatimah Yusof

The Critiques to Positivism Direction of Inquiry in Comprehending the Complexity of Governance in Managing Cities Competitiveness

contained fallible information that leads to myopic thinking. Everyone is trapped under the unruly perceptions, which entail to 'divisional of thought' between workforce, and thus, it further reciprocates to the disintegration of institutional interdependency. Antagonistic relationships between workforce and the management are seemingly dominantly present as organizational culture, even though the "de jure" for good urban management are in place. Justifying the concern on the endemic behaviours where ignorance, resentment and dissonance that are apparent among workforce, it obviously suggests the importance of institutional interdependency embraced in local authorities. Their existence, without any mitigating and purposive responses would lead local authorities into not being a learning organization, in managing cities competitively. However, it is interesting to note, that moving away to interpretivism line of inquiry to understand the reasons of hard failed initiatives sanctioned in local authorities towards efficiency is of valuable. At least, the intangible perspectives would lay the generic framework in determining other unknown, subliminal subjectivities in explaining the circumstances that imbued endemic behaviours in local authorities. Furthermore, it also gives alternative option available for social scientist to identifying the other intervening variables that aptly influenced the level of anticipations [the acceptance or resentment] by workforce involved in sanctioning and executing organizational transformations. As such, the admission to cognitivism-interpretivism line of inquiry is thus justified through the construct of the definitive in-direct causal explanation to the relationships. It is hope, through this insight, all public agencies including local authorities will in better competitive position in acculturating learning values as the enabler to the construct of organizing capacity towards the management for competitive cities as a whole. For one, the findings on the measurements in determining the pattern of governmentality will be elaborated in our next paper.

\section{REFERENCES}

Argyris, C. \& Schon, D. (1978). Organizational Learning: A Theory of Action Perspective, Reading, MA: Addison-Wesley.

Azmizam, A Rashid, Hamzah, J. \& Jalaluddin, A Malek. (2009). Efficient Urban Governance in Managing and Enhancing Competitive of Kuala Lumpur CityRegion. The $4^{\text {th }}$ international Conference of the International Forum on Urbanism. The New urban Question: Urbanism beyond Neo-Liberalism. Amsterdam/Delft.

Babbie, E. R. (2009). The Practice of Social Research. 12 ${ }^{\text {th }}$ Edition. Belmont CA: Wadsworth Publishing.

Baker, G. (2002). Distortion and risk in optimal incentive contracts. Journal of Human Resources, 37(4), 728-751.

Bandura, A. (1997). Self-efficacy: The Exercise of Control. New York: W. H. Freeman

Cohen, S. (1987). From the Maccabees to the Mishnah. Philadelphia: Westminster Press.

De Vaus, D.A (2001). Research Design in Social Research. London: SAGE. 
DiBella, J. A. \& Nevis, E. C. (1998). How Organizations Learns: An Integrated Strategy for Building Learning Capability. San Francisco: Jossey-Bass, Inc.

Durkheim, E. (1893). The Division of Labour in Society. Translator W. D. Halls in (1984). New York: The Free Press.

Elkjaer, B. (1999): In search of a social learning theory. In Easterby-Smith, et al (Eds.), Organizational Learning and the Learning Organization: Development in Theory and Practice. London: SAGE Publications.

Faizul, A (2015). The Learning Organization-Based Local Authorities in Attaining Cities Competitiveness. Unpublished $\mathrm{PhD}$ Thesis, UKM

Festinger, L., Schachter, S. \& Back, K. (1950). Social Pressures in Informal Groups: A Study of Human Factors in Housing. Stanford, CA: Stanford University Press

Foucault, M. (1991). The Faucault Effect: Studies in Governmentality. Harvester Wheatsheaf: Hemel Hempstead.

Hamzah, J. \& Azmizam, A. R. (2008). Efficiency in Urban Governance towards Sustainability and Competitiveness of City: A Case Study of Kuala Lumpur. In World Academy of Science, Engineering and Technology, Issue 40.

Huysman, M. (1999). Balancing Biases: A critical review of the Literature on Organizational Learning. In Easterby-Smith, et al. (Eds). Organizational Learning and the Learning Organization: Development in Theory and Practice. London: SAGE Publications.

Garvin, D. A. (1993). Building a learning Organization. Harvard Business Review, JulyAugust 1993 Issue,79-91.

Habermans, J. (1989). Theory of Communicative Action: A Critique of Functionalist Reason. Oxford: Blackwell.

Ingraham, P. W. \& Jones, V. D. (1999). The Pain of Organizational Change: Managing Reinvention, in Public Management Reform and Innovation: Research, Theory and Application (Edt). Tuscaloosa and London: The University of Alabama Press.

Kaplan, H. B. (2003). Organizational Innovation: Studies of Program Change in Community Agencies. New York: Kluwer Academic/Plenum.

Marquardt, M. J. (2010). Building the Learning Organization. Mastering the Five Element for Corporate Learning. $2^{\text {nd }}$ Edition. Boston: Davies-Black Brealey Publishing.

Marsick, V. J. \& Watkins, K. E. (2005). Facilitating Learning Organizations: Making Learning Count. United Kingdom: Ashgate Publishing Ltd.

Maesen, L.J.G. van der, Walker A.C. \& Keizer, M. (2005). European Network Indicators Social Quality: Final Report. Amsterdam: EFSQ.

Mehta, D. (1998). Urban governance: lessons from best practices in Asia. UMP-Asia Occasional Paper No: 40.

Pedler, M., Burgoyne, J. \& Boydell, T. (1991). The Learning Company: A Strategy for Sustainable Development. London: McGraw-Hill.

Schein, E. H. (1993). Organizational Culture and Leadership. San Francisco: JosseyBass.

Senge, P. (1990): The Fifth Discipline: The Art and Practice of the Learning Organization. New York: Doubleday.

Storper, M. (1998). Regional World Territorial Development in a Global Economy. New York: Guilford Publications, Inc. 
Faizul Abdullah \& Fatimah Yusof

The Critiques to Positivism Direction of Inquiry in Comprehending the Complexity of Governance in Managing Cities Competitiveness

Zuboff, S. (1988). In the Age of the Smart Machine: The Future of Work and Power. New York: Basic Books. 
PLANNING MALAYSIA

Journal of the Malaysian Institute of Planners (2016)

\section{NOTES TO CONTRIBUTORS AND GUIDELINES FOR MANUSCRIPT SUBMISSION}

\section{INTRODUCTION}

The Journal of the Malaysian Institute of Planners or PLANNING MALAYSIA is a multidisciplinary journal related to theory, experiments, research, development, applications of ICT, and practice of planning and development in Malaysia and elsewhere.

The objective of the journal is to promote the activity of town planning through dialogue and exchange of views concerning professional town planning practice. PLANNING MALAYSIA will welcome any news, feature articles, or peer reviewed (including book reviews, software review, etc.) articles for publication. All articles should be original work by the authors. Articles, views and features will not be taken to be the official view of the Malaysian Institute of Planners (MIP) unless it carries the name of MIP as the author. This is to encourage open discussion on diverse issues and opinion for the advancement of town planning practice. Articles and contributions will be accepted from MIP members and non-members worldwide.

In year 2010, PLANNING MALAYSIA Journal has been indexed in SCOPUS. Previous issues of PLANNING MALAYSIA Journal can be viewed on the MIP website.

\section{SUBMISSION OF MANUSCRIPTS}

Manuscript should be emailed to pmjournal@gmail.com. Manuscript should ideally be in the range of 10-12 pages long. Each manuscript should have a title page and an abstract of about 150 words. The title page should contain the title, full name(s), designation(s), organizational affiliation(s), a contact address, and an email address. All manuscripts are received on the understanding that they are not under concurrent consideration at another journal. Exclusive copyright of accepted manuscripts shall be assigned to the Publisher (i.e. the MIP), and in consideration for this, one copy of the current Journal will be provided for each article. Additional reprints of article can be ordered, at cost, by the author(s). PDF format of the article (if available) can be obtained from the Publisher.

\section{LAYOUT}

Manuscript should be typed in single spacing (including footnotes, endnotes and references) on one side of the paper only (preferably A4) with the following margins: right and left $-4.25 \mathrm{~cm}$, top $-5.5 \mathrm{~cm}$ and bottom $-5.2 \mathrm{~cm}$ (including header $-4.5 \mathrm{~cm}$ and footer $-4.3 \mathrm{~cm}$ ) in 11 point Times New Roman font. Footnotes should be numbered consecutively and placed at the end of the manuscript. Footnotes should be kept to a minimum. Tables and diagrams should be provided in the text. References should follow the APA ( $6^{\text {th }}$ Edition) referencing format. All foreign words must be typed and transliterated. The Editorial Board reserves the right to change the transliteration of all historical names, titles and non-English terminology to bring them into conformity with its own style. 


\section{USE OF FORMULA, FIGURES AND TABLES}

Formula (mathematical formula) should be used only when necessary and the conclusions derived must be explained and made intelligible to a non-mathematical reader. Wherever possible, authors are encouraged to place the mathematical parts of the article in an appendix. In cases of empirical articles, authors are expected to make readily available a complete set of data and any specialized computer programs to interested readers.

All illustrations, figures and/or tables in the manuscript must be captioned, in clear black and white (grayscale) and ready for reproduction.

\section{REFEREEING PROCEDURE}

Manuscripts will be acknowledged upon receipt. Only selected (preferred) manuscripts will be reviewed by two (or three) referees in addition to the editors. Editorial decision will normally be made within two to six months, but circumstances beyond control occasionally dictate a longer cycle. If authors are invited to prepare a revision for further consideration, the major issues to be resolved will be outlined and will be forwarded to them as quickly as possible.

\section{ACCEPTED ARTICLES}

Authors of accepted articles will be requested to provide a digital copy of the manuscript, preferably in Microsoft Word to the MIP (the Publisher) via email at pmjournal@gmail.com. MIP will not be responsible for the loss or damage of the digital copy.

\section{COPYRIGHT}

Once published in the PLANNING MALAYSIA, the copyright of the article is automatically vested with the Malaysian Institute of Planners (MIP). The copyright covers the exclusive use of rights to reproduce and distribute the article, including reprints, photographic reproductions, microfilm or any reproduction of a similar nature and translations. Permission to publish illustrations must be obtained by the author before submission. Any acknowledgements should be included in the figure captions.

\section{Contact:}

Editor-in-Chief

PLANNING MALAYSIA

Journal of the Malaysian Institute of Planners

B-01-02, Jalan SS7/13B, Aman Seri, Kelana Jaya,

47301, Petaling Jaya, Selangor Darul Ehsan, MALAYSIA

Tel: +603 78770637 Fax: +60378779636

Email: pmjournal@gmail.com

Homepage: http://www.mip.org.my 


\section{ETHIC STATEMENT}

The Journal of the Malaysia Institute of Planners or PLANNING MALAYSIA is a peerreviewed journal. This statement spells out ethical behaviour of all parties involved in the act of publishing an article for this journal, i.e. the author, the peer-reviewer, the chief editor and editors, and the publisher. This statement is based on COPE's Best Practice Guidelines for Journal Editors. URL: http://publicationethics.org/files/u2 /Best_Practice.pdf

\section{DUTIES OF AUTHORS}

\section{Reporting Standards}

Authors of original research should present an accurate account of the work done as well as an objective discussion of its significance. Data of the research should be represented accurately in the article. An article should contain sufficient detail and references to permit others to replicate the work. Fraudulent or knowingly inaccurate statements constitute unethical behaviour and are unacceptable.

\section{Data Access and Retention}

Authors may be asked to provide the raw data in connection with an article submitted for editorial review, and should be prepared to provide public access to such, if practicable, and should in any event be prepared to retain such data for a reasonable time after publication.

\section{Originality and Plagiarism}

Authors should ensure that they have written entirely original works, and if the authors have used the work and/or words of others this must be appropriately cited or quoted. Such quotations and citations must be listed in the Reference at the end of the article.

\section{Multiple Publication}

An author should not in general publish manuscripts describing essentially the same research in more than one journal or primary publication. Submitting the same manuscript to more than one journal concurrently constitutes unethical publishing behaviour and is unacceptable.

\section{Acknowledgement of Sources}

Proper acknowledgment of the work of others must always be given. Authors should cite publications that have been influential in determining the nature of the reported work.

\section{Authorship of the Paper}

Authorship should be limited to those who have made a significant contribution to the conception, design, execution, or interpretation of the study, and should be listed as coauthors. Others who have participated in certain substantive aspects of the research project, they should be acknowledged or listed as contributors. 


\section{Corresponding Author}

Corresponding author is the author responsible for communicating with the journal for publication. The corresponding author should ensure that all appropriate co-authors and no inappropriate co-authors are included on the paper. All co-authors have seen and approved the final version of the paper and have agreed to its submission for publication.

\section{Acknowledgment of Funding Sources}

Sources of funding for the research reported in the article should be duly acknowledged at the end of the article.

\section{Disclosure and Conflicts of Interest}

All authors should disclose in their manuscript any financial or other substantive conflict of interest that might be construed to influence the results or interpretation of their manuscript.

\section{Fundamental errors in published works}

When an author discovers a significant error or inaccuracy in his/her own published work, it is the author's obligation to promptly notify the journal editor or publisher and cooperate with the editor to retract or correct the paper.

\section{DUTIES OF REVIEWERS}

\section{Contribution of Peer Review}

Peer review assists the chief editor and the editorial board in making editorial decisions while editorial communications with the author may also assist the author in improving the paper.

\section{Unqualified to Review or Promptness}

Any reviewer who feels unqualified to review the assigned manuscript or unable to provide a prompt review should notify the editor and excuse himself/herself from the review process.

\section{Confidentiality}

Manuscripts received for review must be treated as confidential documents. They must not be shown to, or discussed with, others except as authorized by the chief editor. Privileged information or ideas obtained through peer review must be kept confidential and not used for personal advantage.

\section{Standards of Objectivity}

Reviews should be conducted objectively. There shall be no personal criticism of the author. Reviewers should express their views clearly with supporting arguments.

\section{Acknowledgement of Sources}

Reviewers should identify relevant published work that has not been cited by the authors. Any statement that had been previously reported elsewhere should be accompanied by the relevant citation. A reviewer should also call to the chief editor's attention any 
substantial similarity or overlap between the manuscript under consideration and any other published paper of which they have personal knowledge.

\section{Conflict of Interest}

Reviewers should decline to review manuscripts in which they have conflicts of interest resulting from competitive, collaborative, or other relationships or connections with any of the authors.

\section{DUTIES OF EDITORS}

\section{Decision on the Publication of Articles}

The chief editor of the PLANNING MALAYSIA is responsible for deciding which of the articles submitted to the journal should be published. The chief editor may be guided by the policies of the journal's editorial board subjected to such legal requirements regarding libel, copyright infringement and plagiarism. The chief editor may confer with other editors or reviewers in making this decision.

\section{Fair play}

Manuscripts shall be evaluated solely on their intellectual merit.

\section{Confidentiality}

The chief editor/editors and any editorial staff must not disclose any information about a submitted manuscript to anyone other than the corresponding author, reviewers, potential reviewers, other editorial advisers, and the publisher.

\section{Disclosure and conflicts of interest}

Unpublished materials disclosed in a submitted manuscript must not be used by anyone who has a view of the manuscript while handling it in his or her own research without the express written consent of the author. 


\section{PLANNING MALAYSIA JOURNAL: THE PAST ISSUES}

Volume 1, 2003: (http://www.mip.org.my/doc/journal1.pdf)

1. Incorporating Sustainable Development Objectives into Development Plans through Strategic Environmental Assessment

Muhammad Faris Abdullah \& Ishak Ariffin

2. Environmental Concern in Local Planning Practice

Foziah Johar

3. Ecotourism Planning: Who is Really Responsible?

Badarudin Mohammed \& Abdul Aziz. Hussin

4. Towards A Sustainable Built Environment: Environmentally Conscious Planning, Design and Construction

Norhayati Mahyuddin

5. Rural Sustainability: An Examination of the Practice of Sustainable Development Principles in A Rural Community in Malaysia

Ibrahim Ngah

6. Managing Urban Development Process by Using Spatial Information System: A Case Study of $I-$ Space

Alias Abdullah, Muhammad Faris Abdullah \& Fauzan Nordin

7. USM Pushing the Frontier of Town Planning

Lee Lik Meng

8. The Suburbanisation of the Kuala Lumpur Metropolitan Region Jamalunlaili Abdullah

Volume 2, 2004: (http://www.mip.org.my/doc/vol.2-2004.pdf)

1. Creating The Essence of Cities: The Putrajaya's Experience Jebasingam Issace John

2. A Study to Evaluate Child-Friendly Neighbourhoods through a Set of Child-Friendly Indicators Alias Abdullah \& Nik Munerahanim Nik Muhammad

3. The Evaluation of Beaches in Northern Malaysia Badarudin Mohammed, Rahmat Azam Mustafa, Adrin Abdullah, A. Ghafar Ahmad \& Shida Irwana Omar

4. Urban Land Use Change \& the Langat Basin Ecosystem Health Shaharudin Idrus \& Abdul Samad Hadi

5. Application of Land Use Approaches in Controlling Industrial Wastewater Discharge into River Muhammad Faris Abdullah

Volume 3, 2005: (http://www.mip.org.my/doc/vol.3-2005.pdf)

1. Planning Education, Accreditation \& Inter-Professional Links Mohd Thalha Alithamby

2. Electronic Local Authority Management System Tan Thean Siew

3. A Study on the Demand of Spatial Planning \& Decision Support System in Malaysia Muhammad Faris Abdullah, Alias Abdullah, Mansor Ibrahim \& Dazilah Abdul Samad

4. The Technology of Asset Management \& Maintenance Culture in Ensuring Sustainable Development Khairiah Talha \& KC Leong

5. Tessellation Planning \& Honeycomb Housing Mazlin Ghazali, Michael J. Durack \& Mohd Peter Davis

6. The Application of the Concept of Defensible Space for Secured Housing Environment Saari Omar \& Megat Arif Shah Megat Omar

Volume 4, 2006: (http://www.mip.org.my/doc/vol.4-2006.pdf)

1. How We Failed to Plan for Habitability

Lee Lik Meng, Aldrin Abdullah, Tan Sook Fern, Nurwati Badrulzaman \& Ahmad Sanusi Hassan

2. Cairo's Al-Azhar Park: Millennium Development Goals Etched in Green Khaled el-Khishin 
3. Knowledge Cities: Examining the Discourse Smart Villages, Internet Cities Or Creativity Engines Ali A. Alrouf

4. A Preliminary Investigation of A Model On The Decision To Implement Teleworking In The Japanese Business Organisations Abdul Azeez Kadar Hamsa \& Masao Miura

5. An Integration of Multicriteria Analysis with GIS in the Malaysian National Physical Plan Nor Sallehi Kassim \& Rafikul Islam

Volume 5, 2007: (http://www.mip.org.my/doc/vol.5-2007.pdf)

1. Effectiveness of Public Participation Programme: A Feedback from Participants (Sabak Bernam District Local Plan and Kuala Lumpur Structure Plan)

Dasimah Omar \& Oliver Ling Hoon Leh

2. Multicriteria Analysis of Flood Causes in Kuala Lumpur

Nur Fazzillah Muhamed Noordin, Alias Abdullah \& Muhammad Nur Azraei Shahbudin

3. Urban Housing Development: Town Planning Issues

Ibrahim Mohd@Ahmad, Ezrin Arbi \& Ahmad Ramly

4. Sustainable City Planning: Emphasis on the Management of Environmentally Sensitive Areas Halimaton Saadiah Hashim, Joy Jacqueline Pereira \& Ibrahim Komoo

5. The Environment Component in Sustainability Assessment at the Local Level Plan Abdul Hadi Harman Shah, Shaharudin Idrus \& Abdul Samad Hadi

6. Developing a Communicative Planning Approach to Resolve Land Use Conflicts in Jelutong Area of Georgetown, Penang, Malaysia

Mohammad Abdul Mohit \& Raja Mohd. Firdous B. R.M. Harun

7. Komuniti Mapan: Penilaian Tahap Kemapanan Komuniti Orang Asli Temiar Di Negeri Perak Khairul Hisyam B. Kamarudin \& Ibrahim B. Ngah

8. Book Review: "The Boulevard Book" Shu Charng Yen

Volume 6, 2008: (http://www.mip.org.my/doc/vol.6-2008.pdf)

1. Safe City Programme: Are we on the right path to reduce crime? Kamalruddin bin Shamsudin

2. The Contribution of Fiqh al-Jinayat (Islamic Criminal Law) To the Planning of a Safe City Azila Ahmad Sarkawi, Ahmad Basri Ibrahim \& Alias Abdullah

3. Urban Crime and Safe Neighbourhood: Community Perspectives Khairiah Talha

4. Towards A Safe Place for Children in Today's Residential Neighbourhoods Halimaton Saadiah Hashim, Joy Jacqueline Pereira \& Ibrahim Komoo

5. Role of Land Use Planning in Improving Public Health: Way Forward For Malaysia Ainul Jaria Maidin

6. Energy Consumption and Carbon Dioxide Emission Considerations in The Urban Planning Process in Malaysia

Wee Kean Fong, Hiroshi Matsumoto, Chin Siong Ho \& Yu Fat Lun

Volume 7, 2009: (http://www.mip.org.my/doc/journal7.pdf)

1. Urbanization, Environmental Planning and Management: A Challenge for Jamaica. Leiska J. Powell

2. Structural Changes of the Malaysian Economy and Its Spatial Incidence on Regional Economic Growth

Mohammad Abdul Mohit

3. Urban Sustainability and Growth Management in South-East Asian City-Regions: The case of Kuala Lumpur and Hong Kong

Suharto Teriman, Tan Yigitcanlar, Severine Mayere

4. Urban Sprawl in Malaysia: Evidences from Three Largest Metropolitan Areas Jamalunlaili, Mohd. Zulhafidz Yahaya, Mohd Zuwairi Mod Yunus \& Mohd Shakir Md Ali Safudin

5. An Integrated Approach for the Prediction of Water Quality Index Based on Land Use Attributes Using Data Generation Method and Back Propagation Network Algorithm

Faris Gorashi \& Alias Abdullah

6. Groundwater Extraction Modeling for Kuala Lumpur Water Resource Planning 
Pieter E. Stek

7. Power of the Local Authority in Regulating Land Planning and Development Control: Whither Control

Ainul Jaria Maidin \& Bashiran Begum Mobarak Ali

8. Australia Planning Report Card - Telling It Like It Is!

Liz de Chasterl

Volume 8, 2010: (http://www.mip.org.my/doc/vol.8-2010.pdf)

1. Vehicle Ownership and Quality of Life in Urban Residential Neighbourhoods, Northern Peninsular Malaysia

Abdul Ghapar Othman \& Hassim Mat

2. Analysis of Commute Characteristics and Residential Location Choice of IIUM Gombak Campus Employees of Malaysia

Mohammad Abdul Mohit \& Mootaz Munjid Mustafa

3. The Relationship between Urban Population Density and Transportation Fuel Consumption in Malaysian Cities

Neoh Siew Yin \& Ho Chin Siong

4. The Socio-technical Factors in the Use of GIS at the Planning Departments of the Kuala Lumpur City Hall

Mohd Ramzi Mohd Hussain

5. Book Review: Handbook of Research on E-Planning: ICTs for Urban Development and Monitoring, Carlos Nunes Silva (Eds.) IGI Global Publishing Company, Hershey, Pennsylvania, USA (2010). 454 pages. ISBN-13:9781615209293.

Alias Abdullah \& Carlos Nunis Silva

Volume 9, 2011: (http://www.mip.org.my/doc/vol9.pdf)

1. City Development Strategies (CDS) Contribution toward Sustainable Urban Development in Developing Countries

S. Mostafa Rasoolimanesh, Nurwati Badarulzaman \& Mastura Jaafar

2. Urban Residents' Attitude toward Wildlife in Their Neighbourhoods: The Case Study of Klang Valley, Malaysia

Nik Hanita Nik Mohamad

3. Evaluating Stakeholders' Preferences: Reconciling Heritage And Sustainability In Kuala Lumpur Traditional Area

Noor Amila Wan Abdullah Zawawi \& Alias Abdullah

4. Solid Waste Generation Characteristics: The Malaysia Local Authorities' Outlook Muhammad Abu Eusuf, Mansor Ibrahim, Shamzani Affendy Mohd. Din \& Rafikul Islam

5. Urban Air Environmental Health Indicators: A Preliminary Set for City of Kuala Lumpur Oliver Ling Hoon Leh, Shaharuddin Ahmad Kadaruddin Aiyub \& Yaakob Mohd. Jani

6. Classification of Satellite Fused Data for Land Use Mapping in Development Plan Norzailawati Mohd Noor, Alias Abdullah \& Mazlan Hashim

Special Issue I, 2011:

(http://www.mip.org.my/doc/MIP\%20Jurnal\%20Special\%20Issue\%20on\%20Langkawi.pdf)

1. Conservation with Development: Showcasing Langkawi Geopark - An Introduction Halimaton Saadiah Hashim \& Rahimah Abdul Aziz.

2. Geopark for Heritage Conservation: A Need for Integrated Planning and Management Rahimah Abdul Aziz, Halimaton Saadiah Hashim, \& Ibrahim Komoo

3. Implementing Langkawi Geopark through Land Use Planning Noor Yazan Zainol, Hapiz Abd Manap, Ibrahim Yacob, Mahani Muhammad, Mariam Tajuddin \& Ikhwan Mohd Said

4. The Importance of Geological Heritage Resources in Land Use Planning: Experience from Langkawi Geopark Che Aziz Ali \& Tanot Unjah

5. Land Use Planning Statutes for Langkawi Geopark Conservation and Development Sarah Aziz, Halimaton Saadiah Hashim, Rahimah Abdul Aziz, Chan K. L. Geraldine \& Tanot Unjah

6. Potential Biosites of Significant Importance in Langkawi Geopark: Terrestrial Vertebrate Fauna Norhayati, A., Chan, K.O., Daicus, B., Samat, A., Grismer, L.L, \& Mohd Izzuddin, A. 
7. Planning for Heritage Tourism: The Case of Langkawi Geopark Ong Puay Liu \& Sharina Abd Halim

8. Place Making, Place Names, and Local Myths and Legends Rahimah Abdul Aziz \& Ong Puay Liu

9. Introducing Networks in Planning: An Example from Langkawi Chan K. L. Geraldine, Halimaton Saadiah Hashim \& Sarah Aziz

10. Participation towards Heritage Conservation: Case of a Fishing Community in Langkawi Geopark Sharina Abdul Halim, Ong Puay Liu, Nurhafizah Yussof \& Lim Choun Sian

Volume 10, 2012: (http://www.mip.org.my/doc/vol.10-2012.pdf)

1. Determinant Factors of Neighbourhood Quality Norainah Abdul Rahman, Dasimah Omar \& Abdul Ghani Salleh

2. The Relationship between Variations of Grid Layout and Burglary Saniah Ahmad Zaki \& Jamalunlaili Abdullah

3. Analysis of Factors Influencing the Stated Preference of Academic Employees towards Telecommuting in IIUM Campus, Gombak Farah Diyanah Ismail, Abdul Azeez Kadar Hamsa \& Mansor Ibrahim

4. Study on the Potential of Urban Forest Park for Sustainable City Noralizawati Mohamed, Noriah Othman \& Mohd Hisham Ariffin

5. A Study on the Effectiveness of Provision of New Static Information Signage: A Case Study of International Islamic University Malaysia, Gombak Campus Syazwani Sahrir, Syahriah Bachok \& Mariana Mohd. Osman

6. Study the Construction and Demolition Wastes in Klang Valley, Malaysia Muhammad Abu Eusuf, Mansor Ibrahim \& Rafikul Islam

7. The Future of Coastal Management Programme in Malaysia: Making the Coast Visible to Planners M. Zainora Asmawi

Special Issue II, 2013: (http://www.mip.org.my/doc/se2013.pdf)

1. Impacts of Urban Land Use on Crime Patterns through GIS Application Ahmad Nazri Muhamad Ludin, Norsiah Abd. Aziz, Nooraini Hj Yusoff \& Wan Juliyana Wan Abd Razak

2. Estimation of Residential Impervious Surface using GIS Technique M. Rafee Majid, Jamal Aimi Jamaludin \& Wan Yusryzal Wan Ibrahim

3. Green Space Audits on its Accessibility in Pasir Gudang Wan Yusryzal Wan Ibrahim, Ahmad Long \& Ariva Sugandi Permana

4. Firm Dynamic Analysis for Urban Land Use and Economic Growth Modelling Noordini Che’ Man, Soheil Sabri, Nafisa Hosni \& Harry Timmermans

5. Assessment of Neighbourhood Affordability based on Housing and Transportation Costs in Kuala Lumpur, Malaysia Soheil Sabri, Ahmad Nazri M. Ludin \& Foziah Johar

6. Potential Urban Development Parameters that Reduce Energy Consumption in Residential Area Ariva Sugandi Permana, Norsiah Abd. Aziz \& Abd. Razak Jaffar

7. Incorporating Pedestrian Index into Googlemaps Nabila Abdul Ghani, Muhammad Zaly Shah Muhammad Hussein \& Safizahanin Mokhtar

8. Seismic Microzonation for Banda Aceh City Planning Foziah Johar, M. Rafee Majid, Abdul Razak Jaffar \& Adi Safyan Yahya

9. The Reliability Test of Visual Landscape Features Measurement in Highlands Tourism Planning Nafisa Hosni, Nooraini Yusoff \& Hairul Nizam Ismail

Volume 11, 2013: (http://www.mip.org.my/doc/Journal\%202014.pdf)

1. Malaysian Development Plan System: Issues and Problems, One Decade after its Reform (2001-2011) Faizah Ahmad, Ibrahim Mohd., Syra Lawrance Maidin, Rosilawati Zainol \& Norzailawati Mohd Noor

2. Perceptions on Quality of Life in Malaysia: The Urban-Rural Divide Norhaslina Hassan, Noor Ismawati Mohd Jaafar, Raja Noriza Raja Ariffin, Asnarulkhadi Abu Samah \& Mohd Nazari Jaafar

3. Awareness by Kuala Lumpur City Hall Staffs for Successful Implementation of Crime Prevention through Environmental Design (CPTED) 
Shuhana Shamsuddin \& Natasha Azim Hussin

4. Sustainable Forest Management in Lower Kinabatangan, Sabah: Issues and Current Practices Normah Abdul Latip, Nurwati Badarulzaman, Azizan Marzuki \& Mohd Umzarulazijo Umar

5. User's Preference and Perception on the Pedestrian Crossing in Malaysia: The Case of Ampang Road, Kuala Lumpur

Oliver Ling Hoon Leh, Zamila Zamri, Mohd Zamreen Mohd Amin \& Marlyana Azyyati Marzukhi

6. Commuters' Perceptions on Rail based Public Transport Services: A Case Study of KTM Komuter in Kuala Lumpur City, Malaysia

Syahriah Bachok, Mariana Mohamed Osman, Ummi Aqilah Khalid \& Mansor Ibrahim

7. Land Cover Change Detection Analysis on Urban Green Area Loss Using GIS and Remote Sensing Techniques

Norzailawati Mohd Noor, Alias Abdullah \& Mohd Nasrul Hanis Manzahari

8. Analysis of Factors Influencing Use of Motorcars in International Islamic University Malaysia Nelza Lynna Abdul Rahim \& Abdul Azeez Kadar Hamsa

Volume 12, 2014: http://www.mip.org.my/doc/Journal12.pdf

1. Evaluating the Impact of Density on Access to Local Facilities in Urban Neighbourhoods Wan Nurul Mardiah Wan Mohd Rani

2. Town Planners' Perceptions of Sports Facilities and Urban Development: A Case Study of 13 States' Main Sports Facilities in Malaysia

Maassoumeh Barghchi \& Dasimah Bt Omar

3. Disaster Risk Reduction In Malaysian Urban Planning

Intan Afida Mohamad Amin \& Halimaton Saadiah Hashim

4. Conceptualise Tourism Support System through Web-Based GIS for Collaborative Tourism Planning Tarmiji Masron, Azizan Marzuki, Badaruddin Mohamed \& Norizawati Mohd Ayob

5. Integrating Climate Change Mitigation and Adaptation into Spatial Planning: Developing Criteria for Spatial Plan Evaluation in the Selangor River Basin

Chee Ping Ngang, Joy Jacqueline Pereira \& Halimaton Saadiah Hashim

6. Analysis on Community Involvement in Cultural Activities: Transmission of Ethnic Language Aisyah Abu Bakar, Mariana Mohamed Osman, Syahriah Bachok \& Mansor Ibrahim

Special Issue III, 2014: (http://www.mip.org.my/doc/JournalSE3.pdf)

1. Geospatial Technology Approaches in Urban Morphology for Resilient Urban Governance Norzailawati binti Mohd Noor, Marina Mohd Nor, Alias Abdullah \& Rustam Khairi Zahari

2. Sustainable Governance in relation to the Financial Aspect in Managing Coastal Areas: Malaysian Experience

M.Zainora Asmawi, Lukman Hakim Mahamod, Mohd Zin Mohamed \& Tuminah Paiman

3. E-payment at the Local Government Level: A Study of Majlis Bandaraya Shah Alam and Majlis Daerah Kampa Rustam Khairi Zahari, Raja Noriza Raja Ariffin, Nurhawani Zamin \& Norzailawati binti Mohd Noor

4. Residential Satisfaction -Concept, Theories \& Empirical Studies Mohammad Abdul Mohit \& Adel Mahfoud Mubarak Al-Khanbashi

5. Historical Influences to Present Legal Setting of Planning Law in Malaysia Azila Ahmad Sarkawi \& Muhammad Faris Abdullah

6. Understanding of Tourists' Preferences Pattern: A Study in Melaka,Malaysia Syakir Amir, Mariana Mohamed Osman, Syahriah Bachok \& Mansor Ibrahim

7. The Review for the Use of Urban Climatic Map in the Land Use Plan for Urban Planning Illyani Ibrahim, Azizan Abu Samah \& Rosmadi Fauzi

8. Evaluating the Effects of Road Geometrical Design Towards Spot Speed Distribution on Arterial Road

Noor Hafiza Mohd Maksid \& Abdul Azeez Kadar Hamsa

Volume 13, 2015: (http://www.mip.org.my/doc/PMJ2015.pdf)

1. Creative Cities Research in Penang, Malaysia: A Review of Conceptual and Methodological Framework

Khoo Suet Leng, Nurwati Badarulzaman, Narimah Samat, Morshidi Sirat \& Sharifah Rohayah Sheikh Dawood 
PLANNING MALAYSIA

Journal of the Malaysian Institute of Planners (2016)

2. The Role of Fabric Banners for Community Engagement in Digital Era Rosilawati Zainol, Goh Hong Ching, Ibrahim Mohd, Nikmatul Adha Nordin, Siti Maisara Baharom \& Tengku Adeline Adura Tengku Hamzah

3. Thermal Comfort and Energy Solutions for a Better Residential Environment in Malaysia Noor Aziah Mohd Ariffin

4. The Relationship of Human Happiness and Neighbourhood Planning: Case Study Puchong Indah Housing Estate, Selangor, Malaysia Oliver Ling Hoon Leh, Farah Ayuni Marhalim, Siti Nur Afiqah Mohamed Musthafa, Yusfida Ayu Abdullah \& Marlyana Azyyati Marzukhi

5. Assessing the Urban and Rural Stage Bus Services Disparities in Peninsula Malaysia Zakiah Ponrahono, Syahriah Bachok, Mariana Mohamed Osman, Mansor Ibrahim, Muhammad Faris Abdullah \& Alias Abdullah

6. The Roles of Urban Heritage in Determining the Image of the Royal Town of Sri Menanti, Negeri Sembilan Nor Zalina Harun, Dg. Norhidayah Fairuz \& Nor Adilla Nordin

7. Carbon Sequestration through Urban Green Reserve and Open Space Alamah Misni, Sakurah Jamaluddin \& Siti Mazwin Kamaruddin

8. Sustainable Governance in Relation to the Financial Aspect in Managing Coastal Areas: Malaysian Experience

M.Zainora Asmawi, Lukman Hakim Mahamod, Mohd Zin Mohamed, \& Tuminah Paiman

Special Issue IV, 2016: (http://www.mip.org.my/doc/apsa2016.pdf)

1. Mapping Poverty Hot Spots in Peninsular Malaysia Using Spatial Autocorrelation Analysis M. Rafee Majid, Abdul Razak Jaffar, Noordini Che Man, Mehdrad Vaziri \& Mohamed Sulemana

2. Managing Urbanisation and Urban Sprawl in Malaysia by Using Remote Sensing and GIS Applications

Nur Aulia Rosni, Norzailawati Mohd Noor \& Alias Abdullah

3. From Trade Routes to Streets Cultures - An Overview of the Significance and Characteristics of Southeast Asian Traditional Streets Mongkol Khan \& Syed Zainol Abidin Idid

4. Leadership Styles: Incentive or Disincentive Approach in Addressing Street Vendor Problems in Jakarta and Bandung, Indonesia Ariva Sugandi Permana, Norsiah Abd Aziz \& Ho Chin Siong

5. Preservation of Urban Cultural Landscape: Case Study of Roji in Kagurazaka, Tokyo Benika Morokuma

6. Community Perception of Management Goals in Matoushan National Nature Reserve Chengzhao Wu, Tianren Yang, Pei Pei \& Haisu Chen

7. Tripographic Assessment of VFR Travel in Context of Malaysian Domestic Travelers Sharifah Eisyahtun Syed Darar \& Hairul Nizam Ismail

8. Evaluating Significant Factors that Influence Public Transport Usage in Kerman, Iran Azin Bahreini, Hamed Mirzaei, Mehdi Moeinaddini, Zohreh Asadi-Shekari, Muhammad Zaly Shah \& Zahid Sultan

9. Influences of Housing Settings and Designs in Fulfilling the Malay Residents' Social Cultures Noor Aimran Samsudin \& Syed Zainol Abidin Idid

10. The Impact of Iskandar Malaysia Development on Urban Amenities Muhammad Rafeq Razak, Foziah Johar \& Rabiatul Adawiyah Abd Khalil

11. Factor Analysis of Motorcycle Crashes in Malaysia Zahid Sultan, Noor Irdiana Ngadiman, Fara Dela A. Kadir, Nuur Fathin Roslan \& Mehdi Moeinaddini

12. An Overview of Critical Success Factors of Public-Private Partnership in the Delivery of Urban Infrastructure and Services

Zayyanu Muhammad, Kim Kwang Sik, Foziah Johar \& Soheil Sabri

13. The Provision of Vertical Social Pockets for Better Social Interaction in High-Rise Living Siew Bee, Aw \& Poh Im, Lim

14. The Rukun Warga-Based 3Rs and Waste Bank as Sustainable Solid Waste Management Strategy Sherly Towolioe, Ariva Sugandi Permana \& Norsiah A. Aziz, Chin Siong Ho \& Dario G. Pampanga

15. Liveability Planning for Cities: Within the Islamic Framework of Maqasid Al-Shari'ah Norimah Md Dali, Alias Abdullah \& Azila Ahmad Sarkawi 
16. Islamisation of Town Planning Education: A Review on the Courses Offered by the Department of Urban and Regional Planning, International Islamic University Malaysia

Azila Ahmad Sarkawi, Alias Abdullah \& NorimahMd Dali

17. Spatiotemporal Land Use and Land Cover Change in Major River Basins in Comprehensive Development Area

Wan Yusryzal Wan Ibrahim \& Ahmad Nazri Muhamad Ludin

18. Human Behaviour in Open Space around Spring Water in a Central Area of Mito-City in Japan Takayuki Kumazawa

19. Identify Significant Indicators for a Happy City Hamed Mirzaei, Azin Bahreini, Mehdi Moeinaddini, Zohreh Asadi-Shekari, Muhammad Zaly Shah \& Zahid Sultan

20. A Discrete Choice Model for Firm Location Decision Noordini Che' Man \& Harry Timmerman

21. Co-Benefit Modelling and Optimization of Air Pollution Control in Iskandar Malaysia: A Methodology using BenMAP Nadhirah Nordin, M. Rafee Majid, Ho Chin Siong \& Gakuji Kurata

22. Exploring the Implementation and Success of Green Urban Mobility in Asian Cities Zahid Sultan, Nuhu H. Tini \& Mehdi Moeinaddini

23. Analysis of Shrines Properties using Remote Sensing Approach: Case Study of Lembah Bujang Shairatul Akma Roslan, Norzailawati Mohd Noor, Alias Abdullah \& Zuraini Md Ali

24. The Evolvement of Brand Identity of Langkawi Island, Malaysia Mohd Fadil Mohd Yusof \& Hairul Nizam Ismail

25. A Theoretical Overview of Road Hump Effects on Traffic Speed in Residential Environments Khairun Sarah Radhiah Bachok, Abdul Azeez Kadar Hamsa, Mohd Zin Mohamed \& Mansor Ibrahim

26. Implications of Sprawled and Compact Development on Mobility Patterns: A Case-Study of Bhopal, India

Neha Saxena \& Chidambara

27. Research for a Comprehensive and Active Planning Method in an Industrial-Residential Mixed AreaFocused on Ota Creative Town Vision in Ota Ward, Tokyo Taku Nohara, Yu Okamura \& Susumu Kawahara

28. Measuring the Dimensions and Attributes of Liveability of Low-Income Housing Communities in Nigeria

Sule Abass Iyanda \& Mohammad Abdul Mohit

29. An Investigation on the Relationship between Land Use Composition and PM10 Pollution in Iskandar Malaysia

Muhammad Azahar Zikri Zahari, M. Rafee Majid, Ho Chin Siong, Gakuji Kurata \& Nadhirah Nordin

30. Monitoring the Performance of State Structure Plan in Delivering Output using Dynamic Model Muhammad Faris Abdullah, Alias Abdullah, Rustam Khairi Zahari \& Samsuddin Jaafar 